\title{
Capacitor Current Feedback-Based Active Resonance Damping Strategies for Digitally-Controlled Inductive-Capacitive-Inductive-Filtered Grid-Connected Inverters
}

\author{
Iman Lorzadeh ${ }^{1}$, Hossein Askarian Abyaneh ${ }^{1, *}$, Mehdi Savaghebi ${ }^{2}$, Alireza Bakhshai ${ }^{3}$ \\ and Josep M. Guerrero ${ }^{2}$ \\ 1 Center of Excellence in Electrical Power Engineering, Electrical Engineering Department, \\ Amirkabir University of Technology, Tehran 15875-4413, Iran; lorzadeh@aut.ac.ir \\ 2 Department of Energy Technology, Aalborg University, Aalborg East DK-9220, Denmark; \\ mes@et.aau.dk (M.S.); joz@et.aau.dk (J.M.G.) \\ 3 Department of Electrical and Computer Engineering, Queens University, Kingston, ON K7L 3N6, Canada; \\ alireza.bakhshai@queensu.ca \\ * Correspondence: askarian@aut.ac.ir; Tel.: +98-917-228-7310; Fax: +98-21-669-591-95
}

Academic Editor: Chunhua Liu

Received: 31 May 2016; Accepted: 28 July 2016; Published: 17 August 2016

\begin{abstract}
Inductive-capacitive-inductive (LCL)-type line filters are widely used in grid-connected voltage source inverters (VSIs), since they can provide substantially improved attenuation of switching harmonics in currents injected into the grid with lower cost, weight and power losses than their L-type counterparts. However, the inclusion of third order LCL network complicates the current control design regarding the system stability issues because of an inherent resonance peak which appears in the open-loop transfer function of the inverter control system near the control stability boundary. To avoid passive (resistive) resonance damping solutions, due to their additional power losses, active damping (AD) techniques are often applied with proper control algorithms in order to damp the LCL filter resonance and stabilize the system. Among these techniques, the capacitor current feedback (CCF) AD has attracted considerable attention due to its effective damping performance and simple implementation. This paper thus presents a state-of-the-art review of resonance and stability characteristics of CCF-based AD approaches for a digitally-controlled LCL filter-based grid-connected inverter taking into account the effect of computation and pulse width modulation (PWM) delays along with a detailed analysis on proper design and implementation.
\end{abstract}

Keywords: active resonance damping; discrete-time domain; Inductive-capacitive-inductive (LCL)-filter; current control; grid-connected inverter

\section{Introduction}

Due to the increasing emergence of power electronics-interfaced distributed generation (DG) units in modern power distribution systems, control of interfacing inverters has become a very important issue and a flexible and outstanding opportunity for robust integration of renewable energy resources-based DG units with high sustainability, as well as for overcoming the various power quality problems [1-4].

In low-power applications with high switching frequency, a single inductor $\mathrm{L}$ is usually installed in series with the inverter output port in order to attenuate the switching harmonics of the inverter output currents. However, using such a simple topology in high-power applications with low switching frequency, leads to the use of costly and bulky L-filters due to the associated high switching losses. 
Moreover, the dynamic response and harmonic attenuation performance of the inverter, which should comply with the harmonic limitations in standards such as IEEE Std. 519-1992/2014 [5] and IEEE Guide-Adoption of IEC/TR IEC/TR 61000-3-7:2008 [6], may also be affected [7-10]. To overcome these limitations and improve the grid current quality, the inductive-capacitive-inductive (LCL) filter is preferred to its conventional L-type counterpart due to the high attenuation of the converter switching ripples and harmonics that can provide even in high-power conversion systems with low switching frequency, reduction of overall size and cost of the filter, decrease of the filter power losses and better dynamic response [10,11]. Figure 1 illustrates a typical structure of three-phase voltage source inverter (VSI) connected to the grid/load through the popular types of the passive filters.
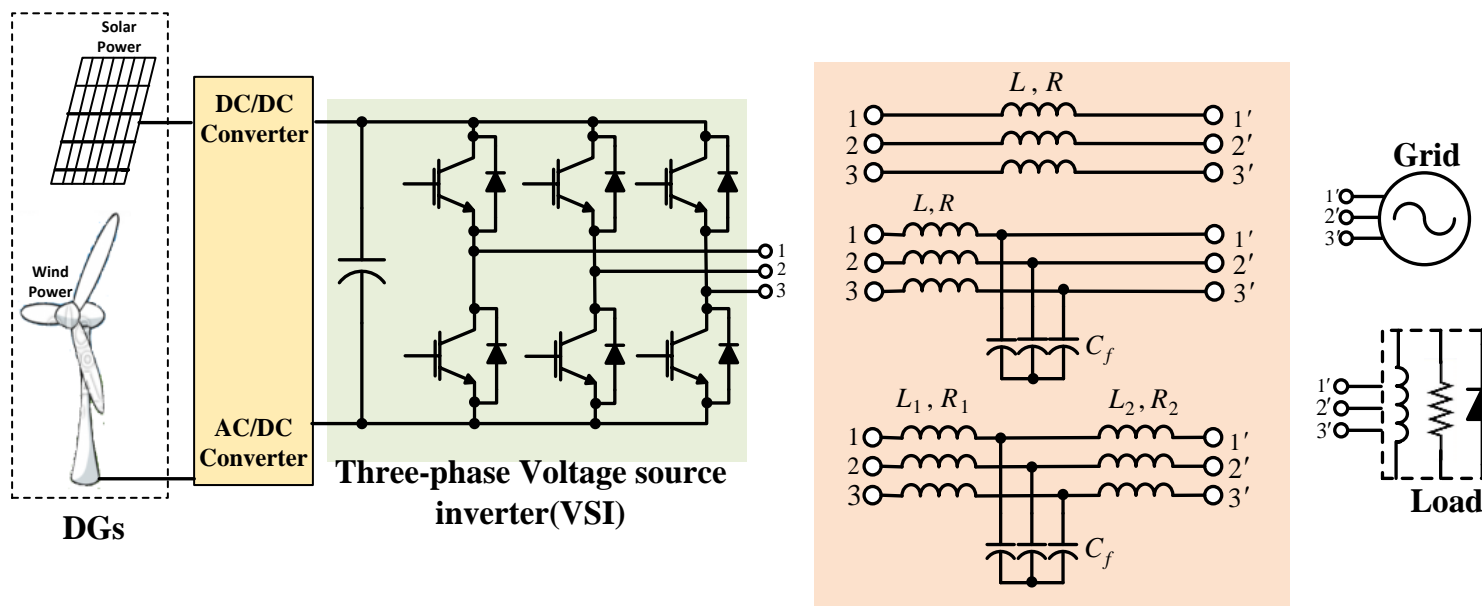

Figure 1. Three-phase voltage source inverter (VSI) connected to grid/load through inductive (L)/inductive-capacitive (LC)/inductive-capacitive-inductive (LCL) filters. DG: distributed generation.

The shunt capacitor in the LCL filter plant is employed to provide a low-impedance path for the high-frequency current components. The LCL filters are broadly used in current-controlled grid-connected VSIs such as active power filters (APFs), and current-controlled DG units, whereas the LC filters are normally adopted for voltage-controlled DG or UPS systems [12]. It is worth pointing out that if these passive high-order filters are not carefully designed, they won't be able to absorb perfect inverter switching harmonics and also may bring additional switching ripples and resonances to the system. It can lead to inappropriate operation of other electromagnetic interference (EMI)-sensitive loads/equipment on the grid $[6,13]$. The general criteria for proper design of high-order filters such as LCL-type are as follows [14-17]:

1) To filter out all of the inverter output harmonics except for the fundamental frequency.

2) To have a cut off frequency much less than the switching frequency of the VSI (which typically should be lower than 0.1 of the switching frequency).

3) To limit the value of the filter inductances in order to reduce voltage drop and increase voltage transfer ratio at the rated current and also improve the voltage quality (by taking a low $\mathrm{d} i / \mathrm{d} t$ for large switching current ripples).

4) To minimize the total reactive power under the rated condition in order to ensure high power factor (should normally be limited to lower than $5 \%-10 \%$ of rated power).

In addition, Shen et al. [18] demonstrated that the LCL-filter provides the maximum attenuation to the high frequency switching ripples when the inverter-side inductor is equal to the grid-side inductors.

Despite the prominent merits of LCL-filter compared to the L-filter, adding it to the inverter terminal leads to remarkable complexity from the perspective of the current control system design to preserve the system stability. In fact, the underlying reason for this is the inherent peak of resonance 
between the filter elements, which introduces a pole pair on the closed-loop control stability boundary owing to zero impedance at the resonance frequency. It may lead to greater susceptibility to interference risks and the lower harmonic impedance introduced to the grid [8,9,19-23]. As a result, this third-order passive filter brings some resonance hazards at the frequency response, which reduce the efficiency and performance of the inverter system and in the worst case even leads to closed-loop system instability. Moreover, if the inverters controller is not properly designed, the resonances may be excited by the control loop, nonlinear loads, disturbances, or transients [14,19], which certainly introduce serious power quality problems for the system. Consequently, one of the most important concerns in the grid-connected inverter system is the inherent resonance caused by the inverter output LCL-filter [10]. Therefore, at first, by using a detailed discrete-time theoretical and stability analysis, this paper explains why and when damping is needed for an LCL filter-based digitally-controlled grid-connected inverter with various resonant frequencies, when computation and pulse width modulation (PWM) delays arising from the nonlinear modulation process and digital sampling are taken into account [23-27]. It is noteworthy that the significance and role of digital sampling and PWM transport delay in design of resonance damping methods for an LCL filtered grid-connected inverter in order to conform more to the actual conditions are of great importance.

There are many well-established methods for shaving the resonance peaks and stabilizing the system, which can be classified as active damping (AD) and passive damping (PD) techniques. It is well known that the PD solutions can be easily realized through adding a real resistor in series or parallel with the output filter elements, especially the filter capacitor branch, to absorb resonance energy and also to maintain the system stability [28]. Its performance, however, is inevitably limited by increased cost, and additional power losses (that can be larger than $1 \%$ of the nominal power in medium voltage applications) [29]. In addition, PD may adversely affect the filter harmonic attenuation efficiency at high frequencies due to the downgrading of the filter plant to a second order system by introducing additional resistors to it $[11,29]$. In other words, since PD hardly inserts damping in a selective way at system resonance frequencies, the filter attenuation at the switching frequency is inevitably compromised. Generally, although PD solution is simple, it will lead to non-compatibility of high-power converters with the EMI standards [18], reduction of system bandwidth as well as the elimination of the benefits introduced by the non-damped filters [11,28]. Recently, to further reduce the filter inductor size, a high-order inductive-inductive-capacitive-inductive (LLCL) filter has been proposed in [30]. In this structure, an inductor is added in series with filter capacitor branch. In addition, various PD methods for LLCL-filter-based grid-tied inverter have been presented in [31,32] by considering the large variation of grid-side inductance. As study of PD strategies is outside the scope of this paper, the different combinations of PD methods are not presented here.

Although effectiveness of the PD solutions have been proven [33], thanks to the significant advances in power electronic technologies, the switching frequency and control bandwidth of the DG interface inverter can be much higher than the resonant frequency of output filters, even for wind power converters at a few megawatts (MW) [16]. Consequently, AD schemes with high efficiency and flexibility and without any additional power losses are often considered as a more promising way to provide sufficient damping to the filter plant in the inverter system. In this way, maximization of the system open-loop gain and increased the system damping can be attained by moving the resonant poles away from the system control stability boundary [11,23]. The aim of $\mathrm{AD}$ schemes is to dynamically modify the inverter output voltage to alleviate the zero impedance impact of LCL-filter at resonant frequency. AD techniques can be broadly classified into two categories. The first group includes digital filters which do not require any additional measurement and placed in cascade with current controller [34]. Plugging-in these filters provides a sensor-less damping scheme, but its performance strongly depends on the precision of system parameters and model (sensitivity to system parameter variations and uncertainties) $[9,11,35,36]$. Performance and design of these damping methods are not investigated in this paper. Another group consists of feedback-type AD approaches which use the feedback of LCL filter state variables such as filter 
capacitor current $[22,23,26,27,37-46] /$ voltage $[8,13,47]$ or the inverter-side current feedback $[11,37]$. The basic idea of these approaches is to feed other control variables back to the existing current control loop, so that they can operate as damping terms in order to suppress the LCL filter resonant peak. It is clear that the implementation of the feedback-type approaches needs additional sensors, which undoubtedly increase overall system cost. In addition, they are provided at the expense of increased complexity of the current controller and damping gains tuning, particularly when computation and PWM delays are taken into account. However, among feedback-type AD techniques, the capacitor current feedback (CCF) AD has attracted considerable attention for its effective LCL resonance damping performance and simple implementation in grid-connected inverters $[27,42,46]$. Hence, this paper conducts an in-depth investigation on this AD method in discrete-time domain by using impedance-based analysis and identifies stability limitations and challenges when computation and PWM delays are taken into account. Consequently, in order to improve the LCL resonance damping performance of conventional CCF AD scheme, two effective techniques along with determination processes of current controller and damping gains are introduced, which so far have not been comprehensively and seamlessly discussed in the literature. It is worthy to note that the analysis conducted in this paper can be useful for exploring and development of other feedback-type $\mathrm{AD}$ methods. Several comparative results are also presented to validate the part of theoretical findings in this paper, which would be efficient for engineers in using this damping method in practical applications.

This paper is organized as follows. In Section 2, the resonance issue caused by the grid-connected VSI with an LCL filter under single-loop grid-side current feedback control scheme will be reviewed under the various resonant frequencies in discrete-time domain when computation and PWM delays are regarded and at the same time, the AD regions will be identified. After that, the conventional proportional CCF AD solution is introduced and analyzed in discrete-time domain by virtual impedance model in Section 3. It is shown that this resonance damping scheme has stability challenges due to the limitation of valid damping region, especially in a weak grid with the potential influence of the grid-impedance variation. Two improved CCF AD methods along with determination processes of current controller and damping gains are then presented in Section 4 to address this limitation and achieve the desired performance characteristics. Finally, this paper will end with a general conclusion in Section 5.

\section{Stability Analysis for Single-Loop-Controlled Inductive-Capacitive-Inductive-Filtered Grid-Connected Inverter with Different Resonant Frequencies}

In this section, the single-loop grid-side current control strategy is analyzed in the discrete-time domain, when computation and PWM delays are considered. This then leads to the identification of two distinct LCL filter resonant frequency regions $[23,26,27]$, which determined when AD is needed for these systems in order to damp the resonance and retain the system stability.

\subsection{Single-Loop Grid-Side Current Control Strategy in Discrete-Time Domain}

\subsubsection{System Description}

Figure 2 shows the structure of an LCL-filter-based grid-connected three-phase inverter including inverter-side inductor $L_{1}$, capacitor $C_{\mathrm{f}}$, grid-side Inductor $L_{2}$, grid inductor $L_{\mathrm{g}}$, inverter output voltage $v_{\text {inv }}$, and grid voltage $v_{\mathrm{g}}$.

It is clear that by neglecting the physical internal damping of the output filter related to winding resistance of the inductors and the equivalent series resistance of filter capacitor as well as the resistive component of grid impedance, which offer a certain degree of damping, the worst case for stability analysis is drawn $[11,19,46]$. 


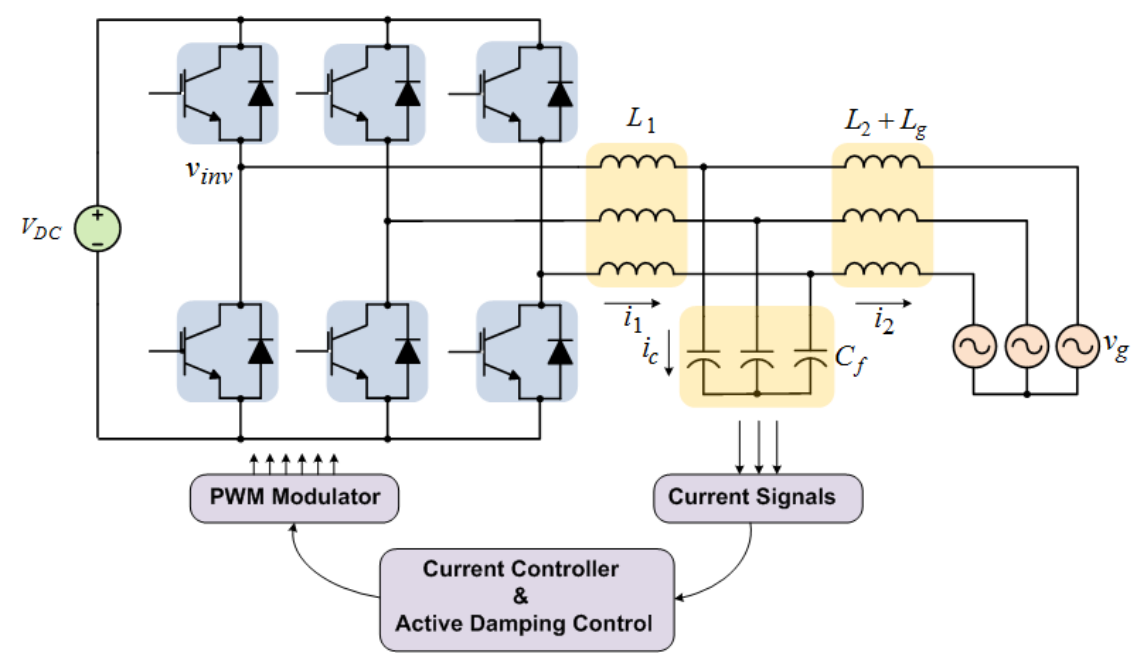

Figure 2. LCL-filter-based grid-connected three-phase inverter structure.

The main aim of the control system is to regulate the grid-side current $i_{2}$ in order to manage the injected active and reactive powers into the grid. However, typically, it has been stated that a single-loop feedback current control scheme is not sufficient for this aim because the LCL filter resonance causes controller instability $[9,22]$. This point will be precisely investigated in the following for different resonance frequencies. Another assumption made here is that the grid voltage $v_{\mathrm{g}}$ only includes positive-sequence fundamental component and thus a clean three-phase balanced grid is considered. It is measured for the purpose of synchronizing the control system by a phase-locked-loop (PLL). Hence, $v_{\mathrm{g}}$ can be regarded as short circuit with zero impedance and removed from modeling block diagrams; since it has not effect on the system stability and harmonic analyses and only influences the fundamental grid-side current component [11,23]. It should be noted that a low-bandwidth synchronizing approach (compared to the grid fundamental frequency) should be applied to avoid the undesired low-frequency instability $[36,48,49]$. By incorporating these conditions, Figure 2 can be simplified to the per-phase equivalent circuit depicted in Figure 3.

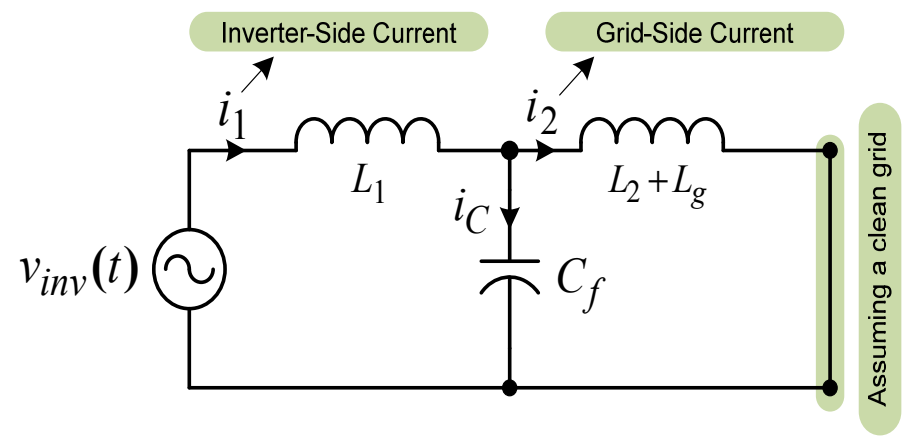

Figure 3. Per-phase equivalent circuit for stability analysis.

Another important practical issue that must be taken into account is that the system actual delays can significantly reduce the phase margin in the high frequency range (the resonance frequencies range) [11,25]. In fact, in the digitally-controlled system, there are computation and PWM delays $[24,25,42]$. When the sampling instant happens at the beginning and in the middle of a switching period (synchronous sampling scheme), the computation delay that is the time duration from the sampling instant to the PWM reference update instant, is considered as one sampling period $T_{\mathrm{s}}$ to avoid the unwanted intermediate PWM transitions [24,32,42]. Since in the synchronous sampling scheme, the fundamental component (the average value per switching period) is obtained, 
the sampling-induced aliasing is not automatically created [42]. Also, since in this sampling scheme, no switching devices are switched at the sampling instant, the switching noise is almost avoided. Because of these advantages, the synchronous sampling scheme is commonly employed in digitally-controlled systems. In addition, the PWM delay, which is caused by zero-order-hold ( $\mathrm{ZOH})$ effect to keep the PWM reference after it has been updated, is approximately considered as half sampling period [25,42]. Thus, in order to investigate the role and importance of the delays in the effectiveness of $\mathrm{AD}$ strategies in digitally-controlled systems, the inverter is well modeled in $z$-domain as a linear $V_{\mathrm{DC}}$ gain with one sample delay $z^{-1}$ created by the nonlinear modulation process [23-25]. Note that the considering a first-order low-pass term as the actual delay term is not appropriate, because the main impact defined by delay is to reduce the phase of the open-loop transfer function, not to decrease amplitude response [23].

Figure 4 illustrates the block diagram of single-loop grid-side current control scheme in s-domain and in discrete-time domain (z-domain) $[22,23,27,36,42,46] . G_{C}(z)$ is the current controller transfer function and $i^{*}(z)$ is the reference grid-side current. The reference grid-side current is generated either from inverter dc-link voltage control loop (for APF systems) or fundamental power reference control (for DG systems).

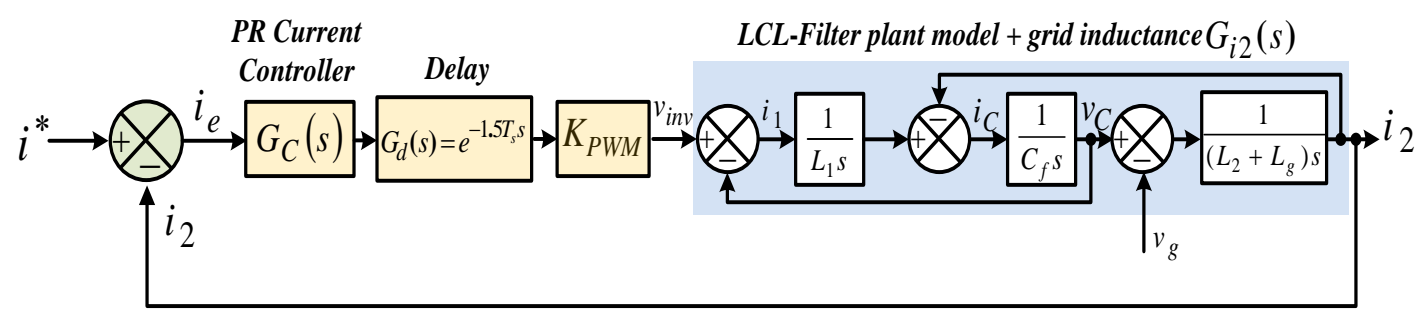

(a)

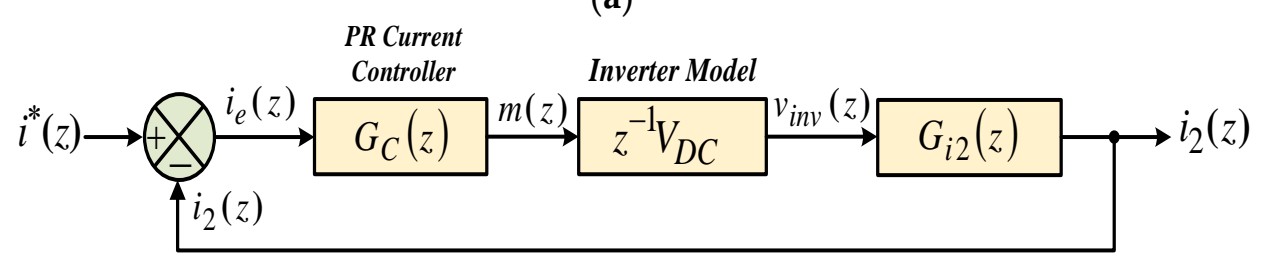

(b)

Figure 4. Block diagram of single-loop grid-side current control scheme without any damping method: (a) s-domain; and (b) z-domain.

The active power reference can be obtained based on the maximum power point tracking (MPPT) in photovoltaic or wind system applications, the maximum system efficiency like in a fuel cell system, or the command from energy management center of a microgrid [3]. The reactive power reference can also be generated from load power factor compensation algorithms or the voltage support requirements. It is worth noting that since the dynamics of the control loop related to the current reference generation is much lower than that of the grid-side current loop, the grid-side current loop can be analyzed separately, resulting in the current reference is directly given as $i^{*}$ here $[23,42]$.

\subsubsection{Stability Analysis}

To explore the resonance and stability issues, firstly, the discrete-time domain control mathematical model of the system shown in Figure 4 is derived. Therefore, by considering Figure 3, the transfer function of $G_{i 2}$ in the s-domain is defined as following [11,22,23]:

$$
G_{i 2}(s)=\frac{i_{2}(s)}{v_{\text {inv }}(s)}=\frac{1}{s L_{1}} \times \frac{\zeta_{L C}^{2}}{s^{2}+\omega_{\text {res }}^{2}}
$$


where $\zeta_{\mathrm{LC}}=\sqrt{1 /\left(\left(L_{2}+L_{\mathrm{g}}\right) \times C_{\mathrm{f}}\right)}$ and $\omega_{\text {res }}=\sqrt{\left(L_{1}+L_{2}+L_{\mathrm{g}}\right) /\left(L_{1} \times\left(L_{2}+L_{\mathrm{g}}\right) \times C_{\mathrm{f}}\right)}$ which is undamped resonance angular frequency and the resonance frequency is $f_{\text {res }}=\omega_{\text {res }} /(2 \pi)$. With applying a $\mathrm{ZOH}$ transform [50] and considering a sampling period of $T_{\mathrm{s}}=1 / f_{\mathrm{s}}$, the transfer function of $G_{i 2}$ in $z$-domain can be calculated as follows $[23,26]$ :

$$
G_{i 2}(z)=\frac{i_{2}(z)}{v_{\text {inv }}(z)}=\frac{T_{\mathrm{s}}}{\left(L_{1}+L_{2}+L_{\mathrm{g}}\right) \times(z-1)}-\frac{\sin \left(\omega_{\text {res }} T_{\mathrm{s}}\right)}{\omega_{\text {res }} \times\left(L_{1}+L_{2}+L_{\mathrm{g}}\right)} \times \frac{z-1}{z^{2}-2 z \cos \left(\omega_{\text {res }} T_{\mathrm{s}}\right)+1}
$$

Usually the controller for three-phase systems is designed under two-phase rotating $(d q)$ or stationary $(\alpha \beta)$ coordinate systems (reference frame). However, for the LCL filter, use of the rotating coordinate system introduces the complex coupling between $d$ - and $q$-axes. As a result, the proportional resonant (PR) controller under stationary frame is often used in LCL filter-based inverter systems in order to track the ac reference current accurately and also to avoid the mentioned strong coupling $[23,25,37]$. A PR controller has a higher bandwidth and an infinite gain at a selected resonant frequency in order to ensure rapid current tracking and remove steady-state error at that frequency [18]. The transfer function for this controller in s-domain can be expressed as:

$$
G_{\mathrm{C}}(s)=K_{\mathrm{p}}+\frac{K_{\mathrm{i}} s}{s^{2}+w_{0}^{2}}
$$

where $K_{\mathrm{p}}$ and $K_{\mathrm{i}}$ are the proportional and resonant coefficients of the current controller, respectively. Furthermore, multiple parallel low-order harmonics resonant controllers [3] can also be added to the current control scheme to provide better harmonic rejection capability. However, it should be noted that when the selected frequency is out of the bandwidth of the system, it may lead to the system instability. This can be one reason for this fact that the harmonic compensators of the PR current controllers are limited to the low-order harmonics [3]. To make damping effects of various AD solutions more obvious, only fundamental PR controller is regarded here in $G_{C}(s)$. The best discretization method for this controller due to its important dynamics is a Tustin (bilinear) approximation with frequency pre-warping [50,51], equivalent to the fundamental frequency, which yields an equivalent discrete-time current controller transfer function as follows [26]:

$$
G_{\mathrm{C}}(z)=K_{\mathrm{p}}+\frac{K_{i} \times \gamma_{z}}{2 \omega_{0}\left(z^{2}-2 z \cdot \cos \left(\omega_{0} T_{\mathrm{s}}\right)+1\right)}
$$

where $\gamma_{z}=\left(z^{2}-1\right) \sin \left(\omega_{0} T_{\mathrm{s}}\right)$.

Notice that the discrete PR controller can also be expressed as Equation (5) [42], so that, its frequency response is similar and coincides with Equation (4) at whole frequency ranges:

$$
G_{\mathrm{C}}(z)=K_{\mathrm{p}}+\frac{K_{\mathrm{i}} \times T_{\mathrm{s}} \times\left(-z^{-2}+z^{-1}\right)}{z^{-2}+\left(\left(T_{\mathrm{s}} \omega_{0}\right)^{2}-2\right) z^{-1}+1}
$$

Then, with combination of these transfer functions, the open-loop gain expression for the single-loop grid-side current control scheme (Figure 4b) can be readily derived as Equation (6) in $z$-domain for applying the control system analysis approaches, such as frequency response (Bode diagram) and root locus analysis:

$$
G_{\text {open_loop }}(z)=\frac{i_{2}(z)}{i_{\mathrm{e}}(z)}=z^{-1} V_{\mathrm{DC}} \times G_{\mathrm{C}}(z) \times G_{i 2}(z)
$$

where $i_{\mathrm{e}}(z)$ is the regulated grid-side current error.

To demonstrate the relationship between the current controller stability and the inherent resonance of the LCL filter, the detailed stability analysis based on the frequency responses of the open-loop gain has been obtained using Equation (6) in MATLAB software environment for the control system shown in Figure 4 b, with the parameters given in Table 1, in which the LCL filter is mainly designed according 
to the criteria presented in [14-17]. Three various filter capacitor values are regarded (Table 1), which can be appropriate choices for consideration of the different regions of LCL resonant frequencies (between $\sim 6.25 \%$ and $\sim 37 \%$ of the sampling frequency). It is worth mentioning that in order to provide an acceptable active resonance damping performance and control bandwidth as well as sufficient switching ripple attenuation, the resonance frequency should be less than half of the Nyquist frequency, which is half of the sampling and the control updating frequency $[7,52]$. The sampling frequency $f_{\mathrm{s}}$ is set to be twice the switching frequency $\left(2 f_{\mathrm{sw}}\right)[26,42,46]$.

Table 1. LCL filter and inverter system parameters.

\begin{tabular}{cccc}
\hline System Parameters & $L_{1}=3.6 \mathrm{mH}$ & $L_{2}=1.8 \mathrm{mH}$ & $L_{\mathrm{g}}=1.8 \mathrm{mH}$ \\
\hline$T_{\mathbf{s}}=\mathbf{1} / f_{\mathrm{s}}=\mathbf{1 0 0} \boldsymbol{\mu s}$ (Sampling Period) & $\omega_{0}=100 \pi$ & $2 V_{\mathrm{DC}}=650 \mathrm{~V}$ & $f_{\mathrm{sw}}=5 \mathrm{kHz}$ \\
\hline \multirow{3}{*}{ Filter Capacitances and Resonance Frequencies } & $C f=36 \mu \mathrm{F}$ & $f_{\text {res }}=0.625 \mathrm{kHz}$ & $f_{\text {res }} / f_{\mathrm{s}}=0.0625$ \\
\cline { 2 - 4 } & $C f=5 \mu \mathrm{F}$ & $f_{\text {res }}=1.67 \mathrm{kHz}$ & $f_{\text {res }} / f_{\mathrm{s}}=0.167$ \\
\cline { 2 - 4 } & $C f=1 \mu \mathrm{F}$ & $f_{\text {res }}=3.751 \mathrm{kHz}$ & $f_{\text {res }} / f_{\mathrm{s}}=0.3751$ \\
\hline
\end{tabular}

Figure 5a,b indicates frequency responses of the single-loop grid-side current control considering the delay effects when the filter resonant frequency is significantly lower than the sampling frequency $\left(C_{\mathrm{f}}=36 \mu \mathrm{F}\right)$ and when the resonant frequency is close to the sampling frequency $\left(C_{\mathrm{f}}=1 \mu \mathrm{F}\right)$, respectively.

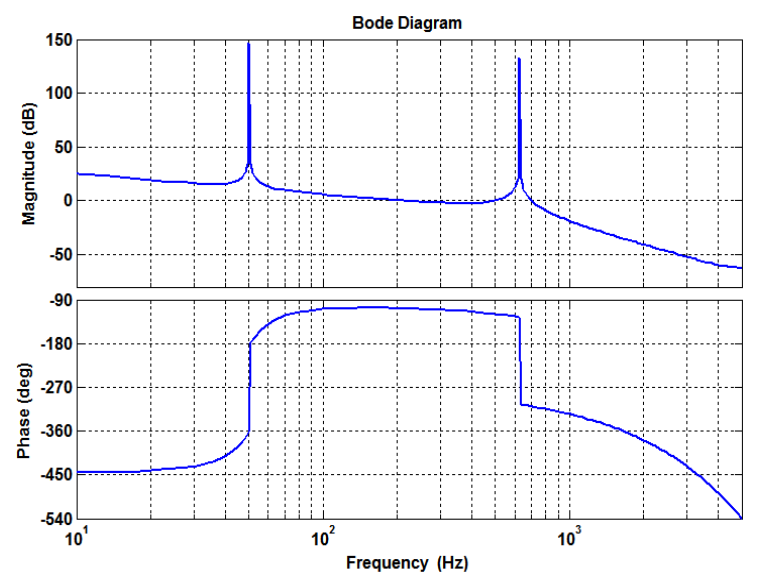

(a)

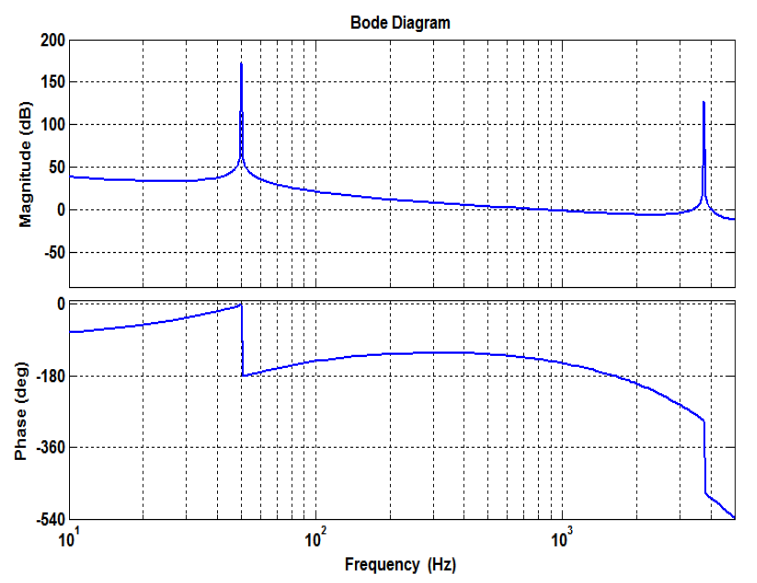

(b)

Figure 5. Bode plots of the open-loop gain in the grid-side current control scheme without any damping method: (a) $C_{\mathrm{f}}=36 \mu \mathrm{F}$; and (b) $C_{\mathrm{f}}=1 \mu \mathrm{F}$.

As seen in Figure 5a, a high-frequency LCL resonance appears in open-loop gain at the frequency $625 \mathrm{~Hz}$ with very high resonant amplitude and a sharp phase transition passing through $-180^{\circ}$. This certainly and unconditionally leads to instability of the closed-loop system for all current controller gains along with a slow dynamic response $[9,22,23,26,27]$. Thus, in this situation, the damping solutions are essential to limit the high gain at the LCL resonance frequency for closed-loop control system stability, even if the physical internal damping terms of the output filter are included. On the contrary, as is well evident from Figure 5b, when the resonant frequency is close to the sampling frequency, the phase of open-loop transfer function moves below $-180^{\circ}$, before the occurrence of the LCL filter resonance frequency (i.e., no Nyquist encirclement of -1 ). Thus, in this case, the system can be stabilized with suitable selection of the proportional gain $K_{\mathrm{P}}$, so that the amplitude response passes through $0 \mathrm{~dB}$ before the resonant frequency (Figure $5 \mathrm{~b}$ ), as long as for any reason, such as the grid impedance variation, the resonance frequency is not reduced to the low resonance frequency region $[26,42,53]$. 
In summary, according to the presented theoretical findings, it can be concluded that for a digitally-controlled LCL-filter-based inverter system with single-loop grid-side current control and filter low-frequency resonances, the control system is unstable and an AD method is required for closed-loop control system stability. In contrast, at high-frequency resonances, the grid-side current feedback only, is adequate to design a conditional stable system with appropriate selection of the current controller proportional gain without any kind of damping method. As a result, it is obvious that there is a critical LCL filter resonance frequency that separates the two frequency regions introduced, so that above this critical resonance frequency, the present current control strategy is sufficient to attain a suitable stable response, but below it, AD is urgent to ensure the system stability. This specific frequency can be easily obtained by calculating the point at which the phase of the open-loop transfer function in Equation (6) cuts - $180^{\circ}$ [23], as seen from Equation (7):

$$
\angle \frac{i_{2}(z)}{i_{\mathrm{e}}(z)}\left(z=\mathrm{e}^{j \omega T_{\mathrm{s}}}\right)=\angle e^{-j \omega T_{\mathrm{s}}} \times V_{\mathrm{DC}} \times G_{\mathrm{C}}\left(\mathrm{e}^{j \omega T_{\mathrm{s}}}\right) \times G_{i 2}\left(\mathrm{e}^{j \omega T_{\mathrm{s}}}\right)=-\pi
$$

Note that, since the PR controller resonant frequency $\omega_{0}$ is much lower than $-180^{\circ}$ crossing-over angular frequency $\omega_{c}$, hence, it has a little phase contribution at this frequency [23,27], and only is considered as a proportional gain $K_{\mathrm{p}}$. Therefore, $\angle G_{\mathrm{C}}\left(\mathrm{e}^{j \omega T_{\mathrm{s}}}\right) \approx 0$. In addition, the resonance of $\mathrm{LCL}$ filter plant makes a phase contribution with value of $-\pi / 2-\omega T_{\mathrm{s}} / 2$ when it is actually reached. Then, by applying these simplifications to Equation (7), $\omega_{\text {crit }}$ can be obtained as follows $[23,26,27]$. It is obvious that the critical resonant frequency becomes equivalent to one-sixth of the sampling frequency $\left(f_{\mathrm{s}} / 6\right)$ :

$$
\angle \frac{i_{2}(z)}{i_{\mathrm{e}}(z)}\left(z=\mathrm{e}^{j \omega T_{\mathrm{s}}}\right)=-\omega T_{\mathrm{s}}-\frac{\pi}{2}-\frac{\omega T_{\mathrm{s}}}{2}=-\pi \Rightarrow \omega_{\text {crit }}=\frac{\pi}{3 T_{\mathrm{s}}} \rightarrow f_{\text {crit }}=\frac{f_{\mathrm{s}}}{6}
$$

Hence, for better understanding of stability issues, the discrete root loci results are also presented. It is worth noting that in this analysis, as previously mentioned, the PR controller $G_{C}(z)$ can be reasonably simplified to $K_{\mathrm{p}}$ since above $\omega_{0}$, the resonant term $K_{\mathrm{i}}$ has insignificant effect in terms of the stability analysis. Thus, the system characteristic equation for the single-loop grid-side current control system, which represents the closed-loop poles, can be obtained by using the conventional $1+G_{\text {open_loop }}(z)=0$ formulation, as:

$$
z+V_{\mathrm{DC}} \times K_{\mathrm{p}} \times G_{i 2}(z)=0
$$

Figure 6 illustrates the movement of closed-loop poles for this digital current control scheme, in different regions of the resonant frequency. As seen from Figure 6a, when the LCL filter resonant frequency is adjusted above $\omega_{\text {crit }}$, the open-loop gain has four poles, which the conjugate closed-loop poles initially move well inside the unit circle. Therefore, the system will be stable until a high enough proportional gain $K_{\mathrm{p}}$ is applied $[9,22,23,26]$. These conjugate poles which are necessary to study the system stability and relate to the resonance frequency $\omega_{\text {res }}$ can be expressed as follows [26]:

$$
P_{\text {Conjugate }}=\cos \left(\omega_{\text {res }} T_{\mathrm{S}}\right) \pm j \sin \left(\omega_{\text {res }} T_{\mathrm{S}}\right)
$$

In contrast, when the resonant frequency is adjusted at or below $\omega_{\text {crit, }}$, the resonant pole pairs always move away from the unit circle (Figure $6 \mathrm{~b}, \mathrm{c}$ ). Thus, in low resonance frequency region, the system is always unstable without using $\mathrm{AD}$, regardless of the $K_{\mathrm{p}}$ values. It is notable that in this case, use of pole-zero compensation method for proper damping of the LCL-filter resonance is very hard; since the system stability is very sensitive to the parameters of the filter [54]. It means that the model-based control approaches are more sensitive to system parameter changes.

In general, this section clearly revealed that why and when damping is needed in a LCL filter-based inverter system with the single-loop grid-side current control scheme for various resonant 
frequencies, while digital sampling and transport delay arising from the controller and nonlinear modulation process are considered. It should also be noted that the single-loop control schemes suffer from low-bandwidth and there is a tradeoff between control dynamics and steady-state performance [37].

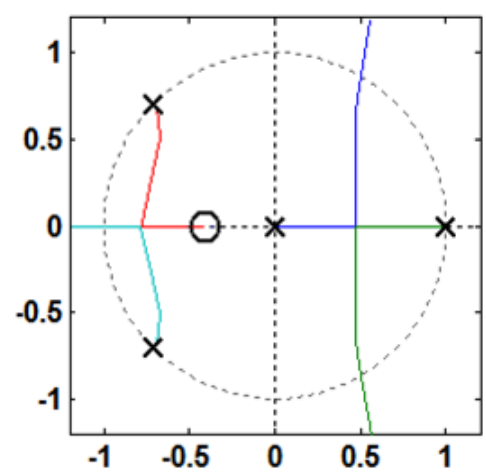

(a)

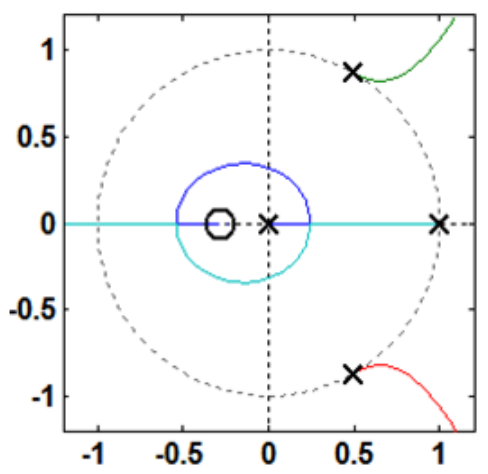

(b)

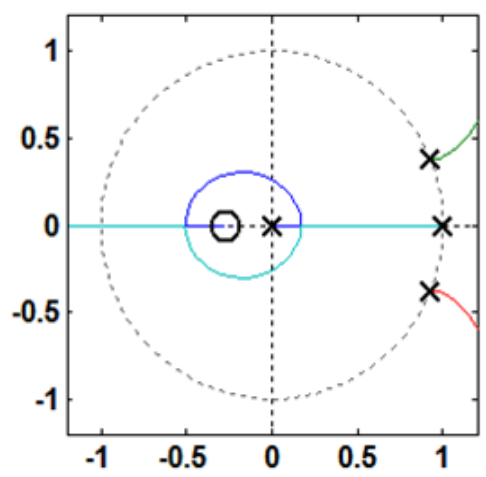

(c)

Figure 6. Root loci of the digital single-loop grid-side current control scheme without any damping method: (a) high resonant frequency region $\left(C_{\mathrm{f}}=1 \mu \mathrm{F}\right) ;(\mathbf{b})$ critical resonant frequency $\left(C_{\mathrm{f}}=5 \mu \mathrm{F}\right)$; and (c) low resonant frequency region $\left(C_{\mathrm{f}}=36 \mu \mathrm{F}\right)$.

\subsection{Current Controller Gains Determination for High Resonant Frequency Region}

As specified above, if the LCL filter resonance frequency is higher than the critical frequency $\omega_{\text {crit }}$, single-loop control with a proper proportional gain $K_{\mathrm{p}}$ is sufficient to attain a conditional stable system. Therefore, in this case, the PR controller defined in Equation (3) can be employed alone to control of the grid-side current without any damping method. Consequently, PR current regulators with suitable gains can thus be designed for this frequency region in order to provide an effective damping effect and the greatest control system bandwidth $[23,27]$. It should be noted that to prevent instability from using an economical choice, the LCL filters are usually installed in practice with a resonance frequency higher than $f_{\mathrm{s}} / 6$ [42-44]. However, in a real grid with the inductive grid impedance, in addition to reducing the resonance frequency, the grid-impedance variation can yield a wide resonance frequency range variation. In view of this, the resonance frequency might reduce to the critical frequency of $f_{\mathrm{s}} / 6$, and thus trigger instability. Hence, the stability challenge in $f_{\mathrm{s}} / 6$ must be resolved to attain high robustness against the variation of grid impedance [42].

As it is clear from Figure 6a, the current controller proportional gain limitation for this frequency region is dependent on the low-frequency poles (delay and series filter inductance effects), not the LCL filter resonance effect, similar to what occurs in simple $L$ filter systems, where $L=L_{1}+L_{2}+L_{\mathrm{g}}$ [23]. Hence, for determining these gains $\left(K_{\mathrm{p}}\right.$ and $\left.K_{\mathrm{i}}\right)$, only low-frequency component of the filter plant model in Equation (2) is needed for the open-loop transfer function in Equation (6) $[11,22,23,25]$, as:

$$
G_{\text {open_loop }}(z)=\frac{i_{2}(z)}{i_{\mathrm{e}}(z)}=z^{-1} V_{\mathrm{DC}} \times K_{\mathrm{p}} \times \frac{T_{\mathrm{s}}}{\left(L_{1}+L_{2}+L_{\mathrm{g}}\right) \times(z-1)}
$$

By considering a desired phase margin $\varphi_{\mathrm{M}}$ and calculating the gain crossover frequency $\omega_{\mathrm{gc}}$ (unity magnitude), the proportional gain $K_{\mathrm{p}}$ can be adjusted to achieve unity gain at the obtained gain crossover frequency, which are described below $[11,22,23,25]$ :

$$
\begin{gathered}
\varphi_{\mathrm{M}}=\pi+\angle G_{\text {open_loop }}\left(z=\mathrm{e}^{j \omega_{\mathrm{gc} T_{\mathrm{s}}}}\right) \\
=\pi+\angle \frac{V_{\mathrm{DC}} \times K_{\mathrm{p}} \times T_{\mathrm{s}}}{\left(L_{1}+L_{2}+L_{\mathrm{g}}\right)} \times \frac{1}{\mathrm{e}^{j \omega \mathrm{gc} T_{\mathrm{s}}} \times\left(\mathrm{e}^{j \omega_{\mathrm{gc} T_{\mathrm{s}}}}-1\right)}=\pi-\omega_{\mathrm{gc}} T_{\mathrm{s}}-\frac{\pi}{2}-\frac{\omega_{\mathrm{gc} T_{\mathrm{s}}}}{2}
\end{gathered}
$$




$$
\begin{gathered}
\varphi_{\mathrm{M}}=\frac{\pi}{2}-\frac{3}{2} \omega_{\mathrm{gc}} \times T_{\mathrm{s}} \\
\rightarrow \omega_{\mathrm{gc}}=\frac{\frac{\pi}{2}-\varphi_{\mathrm{M}}}{\frac{3}{2} T_{\mathrm{s}}}
\end{gathered}
$$

Then:

$$
\left|G_{\text {open_loop }}\left(z=\mathrm{e}^{j \omega_{\mathrm{gc}} T_{\mathrm{s}}}\right)\right|=1 \rightarrow K_{\mathrm{p}} \approx \frac{\omega_{\mathrm{gc}} \times\left(L_{1}+L_{2}+L_{\mathrm{g}}\right)}{V_{\mathrm{DC}}}
$$

Recognizing that the resonant term $K_{\mathrm{i}}$ makes low contribution at the crossover frequency [25], it can be calculated as follows $[11,22,23]$ :

$$
K_{\mathrm{i}} \approx \frac{\omega_{\mathrm{gc}}^{2} \times\left(L_{1}+L_{2}+L_{\mathrm{g}}\right)}{10 V_{\mathrm{DC}}}
$$

Thus, for the high filter resonant frequency included in Table $1(3.751 \mathrm{kHz})$ and a desired phase margin of $\varphi_{\mathrm{M}}=45^{\circ}$, these gains are obtained as $K_{\mathrm{p}}=0.116$ and $K_{\mathrm{i}}=60.736$. This phase margin can be easily identified from Figure $5 \mathrm{~b}$. However, as mentioned previously, in a real grid with inductive grid impedance, which makes the resonance frequency lower; potential instability may be trigged if the grid impedance variation introduced by inductive loads, power transformers, etc., further reduces the resonance frequency to an unstable range (at or below $\omega_{\text {crit }}$ ) $[26,42,55,56]$. Therefore, in general case, when the LCL filter-based inverter system is connected to a weak grid, the stability challenge for this resonance frequency region $\left(f_{\text {res }} \leq f_{\mathrm{s}} / 6\right)$ must be resolved by an effective AD scheme in order to achieve high robustness against the variation of grid impedance $[26,42,53]$.

\section{Proportional Capacitor Current Feedback Active Damping Approach}

Figure 7a,b illustrates the grid-side current control scheme based on CCF AD method via a proportional gain $K_{\mathrm{D}}$ in both $s$ - and $z$-domains, respectively, to address the resonance stability problem. In this Section, firstly, according to the impedance-based basic analysis in s-domain, the physical meaning of proportional CCF AD is well clarified. Then, to design the controller parameters and AD term $\left(K_{\mathrm{D}}\right)$ as well as to confirm the impedance-based analysis, the stability analysis based on the Bode diagram and the root locus in z-domain is presented. In [37], it has been proved that the proportional feedback of filter capacitor current is equivalent to a virtual resistor damper connected in parallel with the passive filter capacitor. This conclusion is, however, drawn without considering the effect of delays, and therefore it is not accurate for digitally controlled systems [26,42,43,46,57]. With regard to the delays' effect, as will be discussed later, the AD scheme based on the proportional CCF should be modeled as virtual impedance, rather than as a pure resistor [43,46,56,57]. It is worth noting that if the relationship between capacitor current and voltage is considered, the capacitor voltage feedback AD methods are generally equivalent to the CCF AD with a minor change. For instance, in $[13,58]$, the filter capacitor voltage has been fed back through a lead-lag filter, which is equivalent to the feedbacks of both filter capacitor current and voltage through low-pass filters[53]. Also, in [59], with prediction of the filter capacitor voltage and feedback through a high-pass filter (HPF), the resulting AD method can be equivalent to the feeding back of filter capacitor current through a low-pass filter. Therefore, for simplicity in explaining the concept, in this paper, the filter CCF AD schemes are considered and based on them, the other state variable feedback AD methods can be developed. 


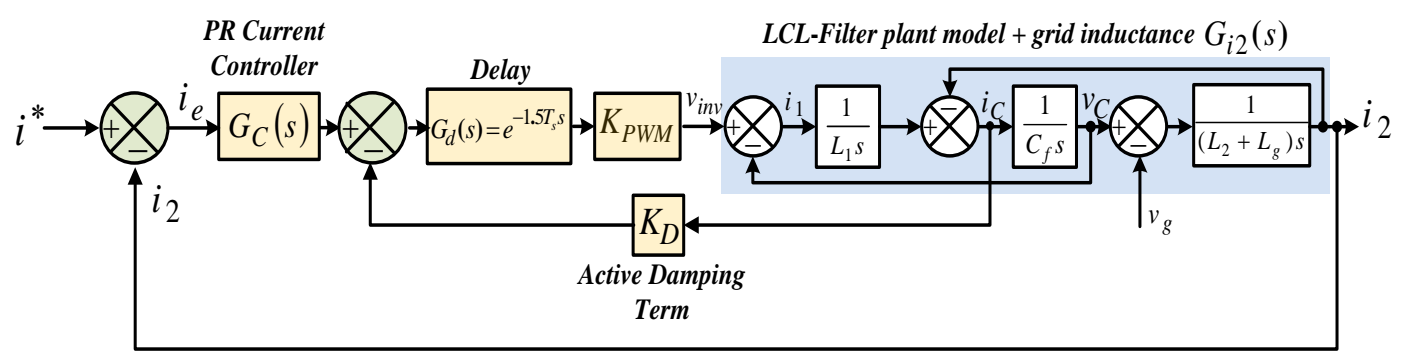

(a)

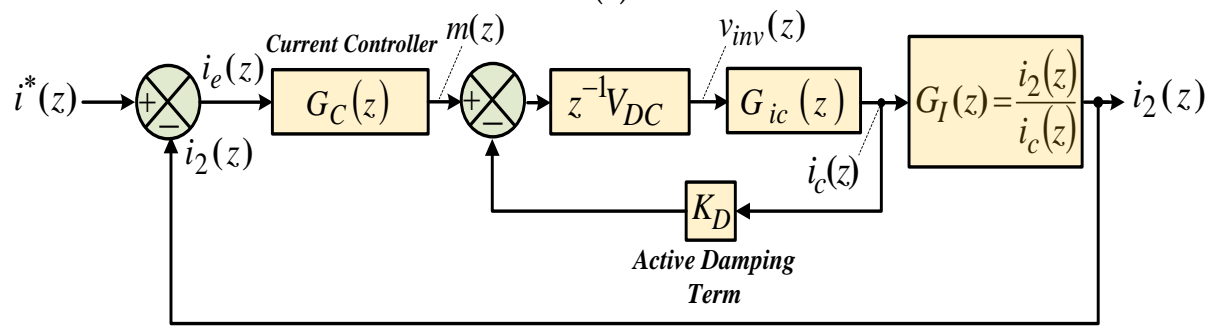

(b)

Figure 7. Block diagram of grid-side current control scheme with proportional capacitor current feedback (CCF) active damping (AD): (a) s-domain; and (b) z-domain.

\subsection{Impedance-Based Analysis}

According to Figure 7a, the inverter output voltage can be expressed as follows:

$$
v_{\text {inv }}(s)=G_{C}(s) \times G_{\mathrm{d}}(s) \times K_{\mathrm{PWM}} \times\left(i^{*}-i_{2}\right)-K_{\mathrm{D}} \times K_{\mathrm{PWM}} \times G_{\mathrm{d}}(s) \times i_{\mathrm{C}}
$$

It is well known from Equation (17) that the filter CCF AD scheme has an interesting circuit physical meaning due to the presence of inverter-side inductor between the inverter output voltage and the filter capacitor branch. This can easily be determined by obtaining $i_{2}$ around the resonance frequency considering Figure 3, as seen from Equation (18). It should be noted that due to the limited bandwidth of the closed-loop current control term, the CCF term $K_{\mathrm{D}} \times K_{\mathrm{PWM}} \times G_{\mathrm{d}}(s) \times i_{\mathrm{C}}$ is regarded as the dominant term around the LCL filter resonance frequency [37]. Hence, this term will regulate the system resonance damping performance:

$$
i_{2}(s)=-\left(\frac{K_{\mathrm{D}} \times K_{\mathrm{PWM}} \times G_{\mathrm{d}}(s) \times i_{\mathrm{C}}(s)+v_{\mathrm{C}}(s)}{s L_{1}}+i_{\mathrm{C}}(z)\right)=-\left(\frac{v_{\mathrm{C}}(s)}{L_{1} /\left(C_{\mathrm{f}} \times K_{\mathrm{D}} \times K_{\mathrm{PWM}} \times G_{\mathrm{d}}(s)\right)}+\frac{v_{\mathrm{C}}(s)}{s L_{1}}+s C_{\mathrm{f}} \times v_{\mathrm{C}}(s)\right)
$$

Further looking into Equation (18) reveals that the AD based on CCF introduces an extra term to output current, which can be well modeled as virtual impedance $Z_{\mathrm{V}}(s)$ parallel with the filter capacitor around the resonant frequency in the continuous s-domain as follows:

$$
Z_{\mathrm{v}}(s)=\frac{L_{1}}{C_{\mathrm{f}} \times K_{\mathrm{D}} \times K_{\mathrm{PWM}} \times G_{\mathrm{d}}(s)}
$$

Therefore, for better demonstration of circuit physical meaning realized by capacitor current proportional feedback AD, its representation in Figure $7 \mathrm{a}$ is redrawn as Figure 8a, while retaining the system closed-loop response unchanged. The modified filter plant in Figure 8a can be eventually considered like the equivalent circuit shown in Figure $8 \mathrm{~b}$ in order to provide sufficient damping into the filter plant when the system delays are included. This representation reveals that the CCF AD is no different from paralleling a virtual impedance $Z_{\mathrm{v}}(s)$ across the filter capacitor $C_{\mathrm{f}}$. As $G_{\mathrm{d}}(s)$ is usually fixed by the chosen sampling frequency, the inserted virtual impedance can be shaped by varying $K_{\mathrm{D}}$. Therefore, from this analysis, it can be easily concluded that if $G_{\mathrm{d}}(s)=1$ (system without delay), the parallel resistive damper $R_{\mathrm{V}}$ can be implemented by $K_{\mathrm{D}}=L_{1} / R_{\mathrm{V}} \times K_{\mathrm{PWM}} \times C_{\mathrm{f}}$, as seen 
in Figure 8c. The modified filter plant shown in Figure $8 \mathrm{~b}$ can also be described in the continuous s-domain as follows:

$$
\begin{gathered}
i_{2}=G_{1}(s) \times v_{\text {inv }}-G_{2}(s) \times v_{\mathrm{g}} \\
G_{1}(s)=\frac{Z_{2}(s) \times Z_{v}(s)}{Z_{1}(s) Z_{2}(s) Z_{v}(s)+Z_{1}(s) Z_{3}(s) Z_{v}(s)+Z_{2}(s) Z_{3}(s) Z_{v}(s)+Z_{1}(s) Z_{2}(s) Z_{3}(s)} \\
G_{2}(s)=\frac{Z_{1}(s) \times Z_{v}(s)+Z_{2}(s) \times Z_{v}(s)+Z_{1}(s) \times Z_{2}(s)}{Z_{1}(s) Z_{2}(s) Z_{v}(s)+Z_{1}(s) Z_{3}(s) Z_{v}(s)+Z_{2}(s) Z_{3}(s) Z_{v}(s)+Z_{1}(s) Z_{2}(s) Z_{3}(s)}
\end{gathered}
$$

where $Z_{1}(s)=s L_{1}, Z_{2}(s)=1 /\left(s C_{\mathrm{f}}\right)$, and $Z_{3}(s)=\left(L_{2}+L_{\mathrm{g}}\right) s$.

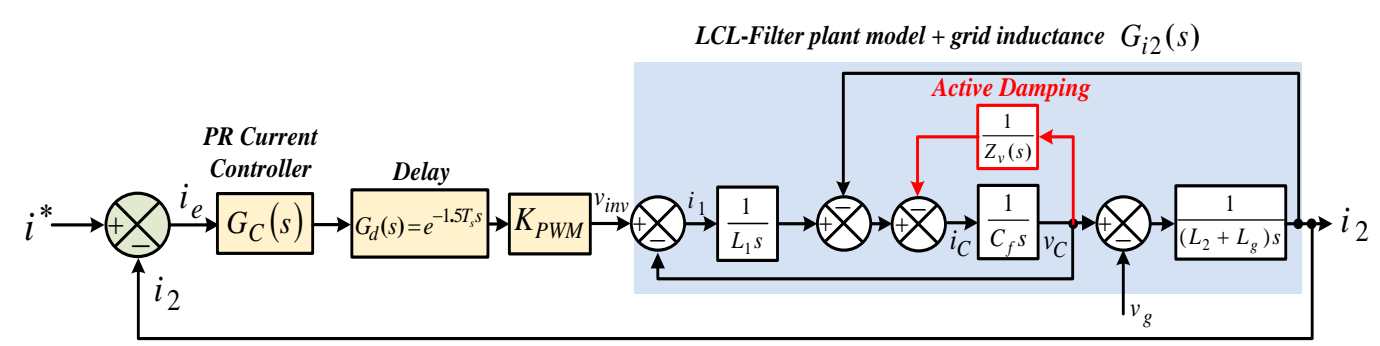

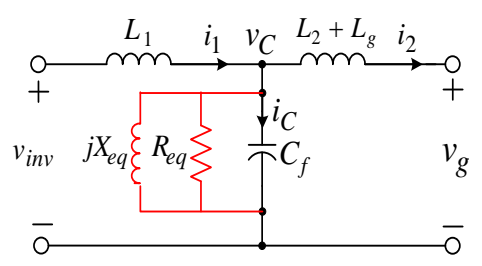

(b)

(a)

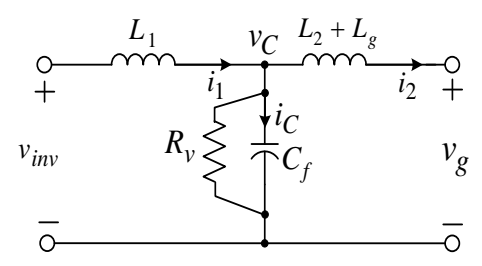

(c)

Figure 8. Equivalent control diagram and filter equivalent circuit for the proportional CCF AD scheme: (a) control diagram representation; (b) filter equivalent circuit with considering system delays; and (c) filter equivalent circuit without considering system delays.

Taking into account the delay effects and using Euler's formula, the embedded virtual impedance is composed as Equation (23) [42]:

$$
\begin{gathered}
Z_{\mathrm{V}}(j \omega)=\operatorname{Re}\left\{Z_{\mathrm{v}}(j \omega)\right\}+j \operatorname{Im}\left\{Z_{\mathrm{V}}(j \omega)\right\} \\
\operatorname{Re}\left\{Z_{\mathrm{v}}(j \omega)\right\}=\frac{L_{1}}{C_{\mathrm{f}} \times K_{\mathrm{D}} \times K_{\mathrm{PWM}}} \times \cos \left(1.5 \omega T_{\mathrm{S}}\right), \operatorname{Im}\left\{Z_{\mathrm{v}}(j \omega)\right\}=\frac{L_{1}}{C_{\mathrm{f}} \times K_{\mathrm{D}} \times K_{\mathrm{PWM}}} \times \sin \left(1.5 \omega T_{\mathrm{s}}\right)
\end{gathered}
$$

Further, $Z_{\mathrm{v}}(j \omega)$ can be rewritten in another form as seen in Equation (24):

$$
\begin{gathered}
Z_{\mathrm{V}}(j \omega)=R_{e q}(\omega) \| j X_{\mathrm{eq}}(\omega) \\
R_{\mathrm{eq}}(\omega)=\frac{L_{1}}{C_{\mathrm{f}} \times K_{\mathrm{D}} \times K_{\mathrm{PWM}} \times \cos \left(1.5 \omega T_{\mathrm{s}}\right)}, X_{\mathrm{eq}}(\omega)=\frac{L_{1}}{C_{\mathrm{f}} \times K_{\mathrm{D}} \times K_{\mathrm{PWM}} \times \sin \left(1.5 \omega T_{\mathrm{s}}\right)}
\end{gathered}
$$

This means $Z_{\mathrm{v}}$ can be considered as parallel connection of a resistor $R_{\mathrm{eq}}$ and a reactor $X_{\mathrm{eq}}$, which both are frequency dependent, as represented in Figure $8 \mathrm{~b}$. The resistive component $R_{\mathrm{eq}}$ is responsible for dampening the LCL-filter resonance peak, whereas, the inductive component $X_{\text {eq }}$ tends to change the resonance frequency. From Equation (24), it is clear that after introducing the delays, both $R_{\mathrm{eq}}$ and $X_{\mathrm{eq}}$ can become positive or negative. As shown in Figure 9, the frequency ranges to have positive and negative $R_{\mathrm{eq}}$ are, respectively, $f<f_{\mathrm{s}} / 6$ and $f_{\mathrm{s}} / 6<f<f_{\mathrm{s}} / 2$ (frequencies between the critical LCL resonance frequency and the Nyquist frequency). In addition, the frequency ranges for inductive or capacitive $X_{\mathrm{eq}}$ are, respectively, $f<f_{\mathrm{s}} / 3$ and $f_{\mathrm{s}} / 3<f<f_{\mathrm{s}} / 2$. The negative resistance will insert open-loop unstable poles to the present current control loop that implies an ineffective $\mathrm{AD}$ method $[27,42,53]$. If a fast dynamic response is also desired, the negative real part causes a non-minimum phase treatment for the closed-loop response, which should preferably be 
resolved [27,36,42,53]. Although, as was demonstrated in Section 2.1.2, AD is not necessary for high resonant frequency region $\left(f>f_{\mathrm{s}} / 6\right)[23,27,57]$, but, it should be noted that the resulting positive resistance damping performance in low frequency region $\left(f<f_{\mathrm{s}} / 6\right)$ and the inherent damping effect in high frequencies $\left(f>f_{\mathrm{s}} / 6\right)$, may be compromised accidentally with arrival of the system actual resonance frequency, respectively, to the critical or high frequency region and low frequency region due to the variation of grid impedance and embedded virtual impedance $[27,42,53]$.

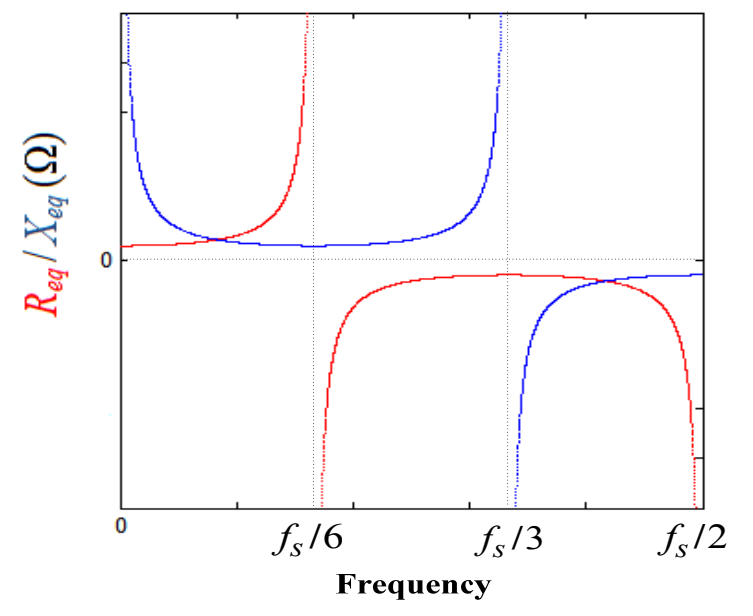

Figure 9. Curves of $R_{\mathrm{eq}}$ and $X_{\mathrm{eq}}$ as the function of frequency.

\subsection{Computation and Pulse Width Modulation Delays Effect on the Resonance Damping Performance}

In this section, the effect of delays on the resonance damping performance is comprehensively investigated to point out the basic challenges and problems in conventional proportional CCF AD method. For performance evaluation of the control system of Figure $7 \mathrm{~b}$, it is needed to have discrete transfer functions of $G_{i c}(z)$ and $G_{\mathrm{I}}(z) . G_{i c}(s)$ is well defined as following [11,22,23]:

$$
G_{\text {ic }}(s)=\frac{i_{\mathrm{c}}(s)}{v_{\text {inv }}(s)}=\frac{1}{L_{1}} \times \frac{s}{s^{2}+\omega_{\text {res }}^{2}}
$$

The transfer function relating $i_{2}$ to $i_{\mathrm{c}}\left(G_{\mathrm{I}}(s)\right)$ can also be easily obtained as the ratio of Equations (1) and (25) as:

$$
G_{\mathrm{I}}(s)=\frac{i_{2}(s)}{i_{\mathrm{c}}(s)}=\frac{G_{i 2}(s)}{G_{i \mathrm{c}}(s)}=\frac{\zeta_{\mathrm{LC}}^{2}}{s^{2}}
$$

Similarly, applying a ZOH transform [50] to Equation (25) and consider a sampling period of $T_{\mathrm{s}}=1 / f_{\mathrm{s}}$, gives $z$-domain transfer function for $i_{\mathrm{c}}$ to $v_{\text {inv }}$ as:

$$
G_{\text {ic }}(z)=\frac{i_{\mathrm{c}}(z)}{v_{\text {inv }}(z)}=\frac{\sin \left(\omega_{\text {res }} T_{\mathrm{s}}\right)}{\omega_{\text {res }} \times L_{1}} \times \frac{z-1}{z^{2}-2 z \cos \left(\omega_{\text {res }} T_{\mathrm{S}}\right)+1}
$$

It is worth nothing that for the synchronous sampling case, the capacitor and grid-side currents are sampled at the same time instants and also the grid-side current in Figure $7 \mathrm{~b}$ comes from the cascaded connection of $G_{i c}(z)$ and $G_{I}(z)$; hence additional delay should not be regarded again to the system model by $G_{\mathrm{I}}(z)$, since delay considered in this process is already accounted for Equation (27) by the $\mathrm{ZOH}$ transformation [23]. As a result, to discretize Equation (26), the impulse-invariant transformation can be used [50], which gives:

$$
G_{\mathrm{I}}(z)=\frac{i_{2}(z)}{i_{c}(z)}=\frac{\zeta_{\mathrm{LC}}^{2} \times T_{\mathrm{s}}^{2} z}{(z-1)^{2}}
$$


The derived transfer functions can then be combined to create open-loop gain expression for the control system of Figure $7 \mathrm{~b}$ as Equation (29) in order to investigate the stability issue based on $z$-domain Bode diagram and root locus analysis:

$$
G_{\text {open_loop }}(z)=\frac{i_{2}(z)}{i_{e}(z)}=\frac{V_{\mathrm{DC}} \times G_{\mathrm{C}}(z) \times G_{\mathrm{I}}(z) \times G_{i c}(z)}{z+V_{\mathrm{DC}} \times G_{\mathrm{ic}}(z) \times K_{\mathrm{D}}}
$$

Then, according to Equation (29), the open-loop (inner proportional CCF loop only) and closed-loop characteristic equations for this $\mathrm{AD}$ control scheme can be respectively written as:

$$
\begin{gathered}
z+K_{\mathrm{D}} \times V_{\mathrm{DC}} \times G_{i \mathrm{c}}(z)=0 \\
z+K_{\mathrm{D}} \times V_{\mathrm{DC}} \times G_{i \mathrm{c}}(z)+K_{\mathrm{P}} \times V_{\mathrm{DC}} G_{i \mathrm{c}} \times(z) \times G_{\mathrm{I}}(z)=0
\end{gathered}
$$

Figure 10 illustrates Bode diagrams of the open-loop gain $G_{\text {open_loop }}(z)$ for different resonant frequencies. It is worth mentioning that for each resonance frequency $f_{\text {res }}$, the parameters of current controller have been designed based on the phase margin of $P M=45^{\circ}$ at $\omega_{\mathrm{gc}} \approx 0.3 \omega_{\text {res }}$ to achieve a satisfactory transient performance [11]. As seen from the Figure, with the increase of the damping term $K_{\mathrm{D}}$, both amplitude and phase plots vary substantially. As it is shown in Figure 10a,b and is clear from Equation (24), in the range $\left(0, f_{\mathrm{s}} / 3\right)$, with increase of $K_{\mathrm{D}}$, a higher actual resonance frequency $f_{\text {res }}^{\prime}$ is generated. In contrast, in the range $\left(f_{\mathrm{s}} / 3, f_{\mathrm{s}} / 2\right)$, with $K_{\mathrm{D}}$ increase, a lower $f_{\text {res }}^{\prime}$ is created (Figure 10c). Since the frequency boundary of $X_{\text {eq }}$ is $f_{\mathrm{s}} / 3$ (Figure 9 ), $f_{\text {res }}^{\prime}$ will only approach to $f_{\mathrm{s}} / 3$ and never exceed it.

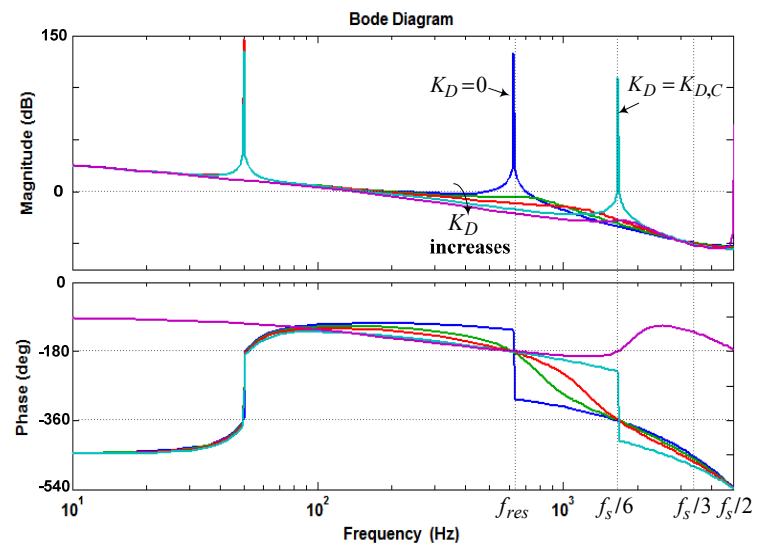

(a)

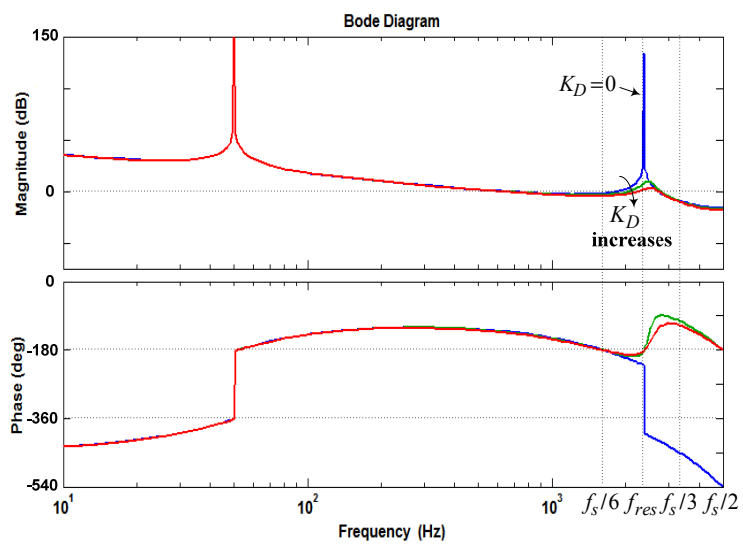

(b)

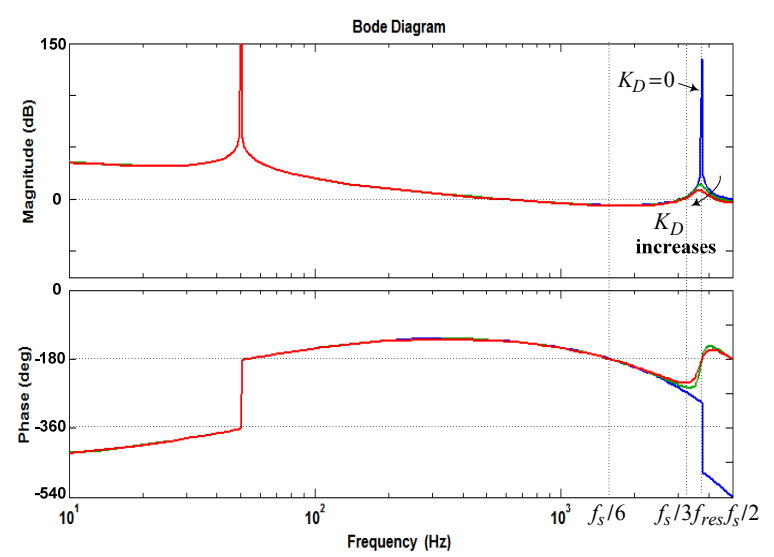

(c)

Figure 10. Bode plots of the open-loop gain in the grid-side current control scheme with proportional CCF AD method: (a) $f_{\text {res }}<f_{\mathrm{s}} / 6 ; C_{\mathrm{f}}=36 \mu \mathrm{F} ; K_{\mathrm{p}}=0.0261 ; K_{\mathrm{i}}=3.0769 ;(\mathbf{b}) f_{\mathrm{s}} / 6<f_{\text {res }}<f_{\mathrm{s}} / 3 ; C_{\mathrm{f}}=2.5 \mu \mathrm{F}$; $K_{\mathrm{p}}=0.0991 ; K_{\mathrm{i}}=44.3077 ;$ and $(\mathrm{c}) f_{\mathrm{s}} / 3<f_{\text {res }}<f_{\mathrm{s}} / 2 ; C_{\mathrm{f}}=1 \mu \mathrm{F} ; K_{\mathrm{p}}=0.1566 ; K_{\mathrm{i}}=110.7692$. 
Also, Figure 11 indicates the poles movement for only the inner proportional CCF, for different resonance frequencies by using the open-loop characteristic equation of Equation (30). It can thus be seen how the resonance poles retain inside unit circle in low resonant frequency $\left(f_{\text {res }}<f_{\mathrm{s}} / 6\right)$ to make a damping contribution unless too large damping gain $K_{\mathrm{D}}$ is applied (Figure 11a). Obviously, there is a maximum useful damping gain, beyond which the stability of overall system will be compromised. As seen in Figures 10a and 11a, for a specific $K_{\mathrm{D}}$, $f_{\text {res }}^{\prime}$ might exceed $f_{\mathrm{s}} / 6$. Thus, this $K_{\mathrm{D}}$ value can be obtained so that the magnitude of the transfer function used in root locus analysis becomes equal to unity for a specific pole $z_{0}=0.5+j \sqrt{3} / 2$, i.e.,

$$
\left|K_{\mathrm{D}} \times V_{\mathrm{DC}} \times G_{i \mathrm{c}}(z)\right|_{z=z_{0}}=1
$$

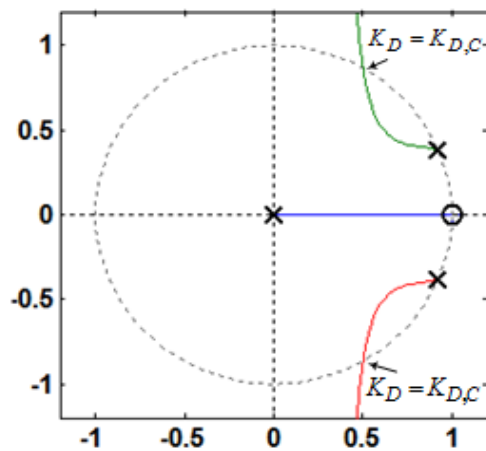

(a)

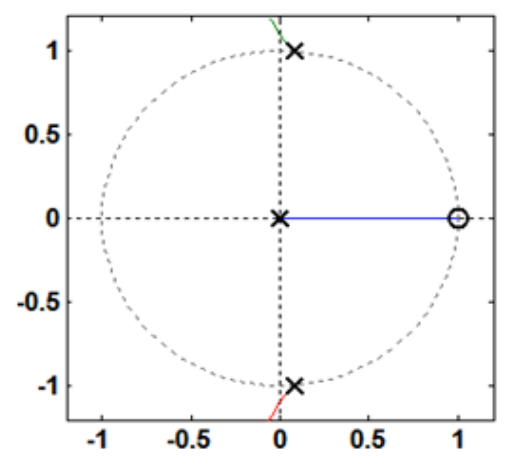

(b)

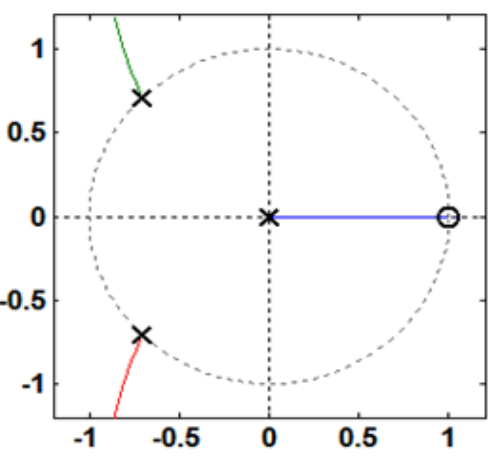

(c)

Figure 11. Root loci of the inner proportional CCF only (open-loop characteristic equation): (a) $f_{\text {res }}<f_{\mathrm{s}} / 6 ; C_{\mathrm{f}}=36 \mu \mathrm{F}$; (b) $f_{\mathrm{s}} / 6<f_{\text {res }}<f_{\mathrm{s}} / 3 ; C_{\mathrm{f}}=2.5 \mu \mathrm{F}$; and (c) $f_{\mathrm{s}} / 3<f_{\text {res }}<f_{\mathrm{s}} / 2$; $C_{\mathrm{f}}=1 \mu \mathrm{F}$.

By solving Equation (32), $K_{\mathrm{D}, \mathrm{C}}$ can be found as Equation (33) [42]:

$$
K_{\mathrm{D}, \mathrm{C}}=\frac{\omega_{\mathrm{res}} \times L_{1}}{V_{\mathrm{DC}} \times \sin \left(\omega_{\mathrm{res}} T_{\mathrm{s}}\right)} \times\left|1-2 \cos \left(\omega_{\mathrm{res}} T_{\mathrm{s}}\right)\right|
$$

Generally, after a detailed investigation of the open-loop gain Bode diagrams and root loci of the inner proportional CCF only shown in Figures 10 and 11, the key features can be summarized as follows:

1) If $f_{\text {res }}<f_{\mathrm{s}} / 6$ and $0<K_{\mathrm{D}}<K_{\mathrm{D}, \mathrm{C}}$, i.e., $f_{\text {res }}^{\prime}<f_{\mathrm{s}} / 6, R_{\text {eq }}$ is positive at $f_{\text {res }}^{\prime}$ (Figure 9), and no open-loop unstable poles exists, as seen in Figure 11a. Hence, the phase plot crosses over $-180^{\circ}$ only at $f_{\text {res }}$ in the direction of phase decrease as shown in Figure 10a. In addition, if $f_{\text {res }}<f_{\mathrm{s}} / 6$ and $K_{\mathrm{D}}=K_{\mathrm{D}, \mathrm{C}}$, i.e., $f_{\text {res }}^{\prime}=f_{\mathrm{s}} / 6, R_{\text {eq }}$ is infinite at $f_{\text {res }}^{\prime}$ (Figure 9 ), and no open-loop unstable poles exists, as seen in Figure 11a. In this case, it has no contribution to the resonance damping performance, and the phase plot also crosses over $-180^{\circ}$ only at $f_{\text {res }}$ in the direction of phase decrease (Figure 10a). As it is known well, for evaluating the stability, in the open-loop Bode diagram, the frequency ranges with amplitude above $0 \mathrm{~dB}$ must be investigated. In these frequency ranges, a $-180^{\circ}$ crossing in the direction of phase increase is considered as a positive crossing $\mathrm{N}^{+}$if the gain margin at that $-180^{\circ}$ crossover frequency is smaller than $0 \mathrm{~dB}$, and a $-180^{\circ}$ crossing in the direction of phase decrease is considered as a negative crossing $N^{-}$if the gain margin at that $-180^{\circ}$ crossover frequency is smaller than $0 \mathrm{~dB}[42,50]$. According to the Nyquist stability criterion [50], to ensure the system stability, the value of $2\left(N^{+}-N^{-}\right)$must be equal to the number of the open-loop unstable poles, otherwise, the system gets unstable. For $f_{\text {res }}<f_{\mathrm{s}} / 6$ and $0<K_{\mathrm{D}} \leq K_{\mathrm{D}, \mathrm{C}}$, i.e., $f_{\text {res }}^{\prime} \leq f_{\mathrm{s}} / 6$, the value of $\left(N^{+}-N^{-}\right)$is equal to zero since the gain margin at $-180^{\circ}$ crossover 
frequency $\left(f_{\text {res }}\right)$ is greater than $0 \mathrm{~dB}$, as seen from Equation (34) (in $\mathrm{dB}$ ). This means that the system will be stable in this frequency region:

$$
G M_{1}=-20 \log \left|G_{\text {open_loop }}\left(\mathrm{e}^{j \omega_{\text {res }} T_{\mathrm{s}}}\right)\right|_{G_{\mathrm{C}}(z)=K_{\mathrm{P}}} \mid=20 \log \left(\frac{K_{\mathrm{D}}}{K_{\mathrm{P}} \times \zeta_{\mathrm{LC}}^{2} \times T_{\mathrm{S}}^{2}}\right)
$$

For $K_{\mathrm{D}}=K_{\mathrm{D}, \mathrm{C}}, C_{\mathrm{f}}=36 \mu \mathrm{F}, K_{\mathrm{p}}=0.0261$, and $L_{2}=L_{\mathrm{g}}=1.8 \mathrm{mH}$, the gain margin $G M_{1}$ in $\mathrm{dB}$ is 33.565 . 2) If $f_{\text {res }}<f_{\mathrm{s}} / 6$ and $K_{\mathrm{D}}>K_{\mathrm{D}, \mathrm{C}}$, i.e., $f_{\text {res }}^{\prime}>f_{\mathrm{s}} / 6, R_{\mathrm{eq}}$ is negative at $f_{\text {res }}^{\prime}$ (Figure 9 ), and a pair of open-loop unstable poles appears (non-minimum phase behavior in the closed-loop response), as seen in Figure 11a. In this case, the phase plot crosses over $-180^{\circ}$ both at $f_{\text {res }}$ and $f_{\mathrm{s}} / 6$, respectively, in the direction of phase decrease and phase increase as shown in Figure 10a. Hence, according to the Nyquist stability criterion, to ensure the system stability, the value of 2( $\left.N^{+}-N^{-}\right)$ must be equal to 2 . It means that the gain margin at $f_{\text {res }}$ and $f_{\mathrm{s}} / 6$, respectively, must be greater and smaller than $0 \mathrm{~dB}\left(G M_{1}>0 \mathrm{~dB}\right.$ and $\left.G M_{2}<0 \mathrm{~dB}\right)$, i.e., $N^{-}=0$ and $N^{+}=1$. The gain margin in $\mathrm{dB}$ at $f_{\mathrm{s}} / 6$ can be derived from Equation (29) as Equation (35). By comparing Equations (34) and (35), one can easily understand that $G M_{1}$ and $G M_{2}$ will be equal, if $f_{\text {res }}=f_{\mathrm{s}} / 6$ :

$$
G M_{2}=-20 \log \left|G_{\text {open_loop }}\left(\mathrm{e}^{j \pi / 3}\right)\right|_{G_{\mathrm{C}}(z)=K_{\mathrm{P}}}|=20 \log | \frac{\omega_{\text {res }} \times L_{1} \times\left(1-2 \cos \omega_{\text {res }} T_{\mathrm{s}}\right)}{K_{\mathrm{P}} \times V_{\mathrm{DC}} \times \zeta_{\mathrm{LC}}^{2} \times T_{\mathrm{s}}^{2} \times \sin \omega_{\text {res }} T_{\mathrm{S}}}+\frac{K_{\mathrm{D}}}{K_{\mathrm{P}} \times \tau_{\mathrm{LC}}^{2} \times T_{\mathrm{s}}^{2}} \mid
$$

3) If $f_{\text {res }} \geq f_{\mathrm{s}} / 6$ and $K_{\mathrm{D}}>0$, i.e., $f_{\text {res }}^{\prime}>f_{\mathrm{s}} / 6, R_{\text {eq }}$ is negative at $f_{\text {res }}^{\prime}$ (Figure 9 ), and a pair of open-loop unstable poles appears, as seen in Figure $11 \mathrm{~b}$,c. In this case, the phase plot crosses over $-180^{\circ}$ both at $f_{\mathrm{s}} / 6$ and $f_{\text {res }}$, respectively, in the direction of phase decrease and phase increase as seen in Figure 10b,c. Hence, to stabilize the system, $G M_{1}<0 \mathrm{~dB}$ and $G M_{2}>0 \mathrm{~dB}$ are both needed.

Figure 12 indicates the effect of proportional CCF AD on the single-loop grid-side current control scheme (Figure 7) for a fixed $K_{\mathrm{P}}$ value at different resonance frequency ranges. As seen in Figure 12a,b, when the LCL resonant frequency is equal or below the critical resonant frequency $\omega_{\text {crit }}$, the resonance poles always originate outside the unit circle, and thus, without $\mathrm{AD}$, the system will be initially unstable. In low resonance frequency region, the poles track back inside the unit circle with increasing the damping gain $K_{\mathrm{D}}$, and hence, the overall system becomes stable unless too large damping gain is applied, as seen in Figure 12a. Clearly, there are minimum and maximum values for damping gain $K_{\mathrm{D}}\left(K_{\mathrm{D}, \min }, K_{\mathrm{D}, \max }\right)$ that ensures the resonant poles, as far as possible, remain inside the unit circle to retain the system stability. This bounded rang will be determined in the Section 3.4. It is also important to note that for $K_{\mathrm{D}, \mathrm{C}} \leq K_{\mathrm{D}} \leq K_{\mathrm{D} \text {, } \max }$, the gain margin requirements $G M_{1}>0 \mathrm{~dB}$ and $G M_{2}<0 \mathrm{~dB}$ can be satisfied by proper selection of $K_{\mathrm{P}}$ to achieve a stable system (Figure 12a). In contrast, when the LCL resonant frequency is equal to $\omega_{\text {crit }}$, as seen from Figure $12 b$, AD can only lead to the resonant poles touching the unit circle, but never entering the circle. Therefore, at the critical resonance frequency, it is essentially not possible to design a current control scheme with AD to stabilize the system, and consequently, the system will always remain unstable irrespective of the applied damping gain [23,42]. In addition, as shown in Figure 12c, when the LCL resonant frequency is above $\omega_{\text {crit }}$, the poles initially are inside the unit circle, as was discussed in previous section, and hence, with proper selection of $K_{\mathrm{P}}$, the system will be initially stable without $\mathrm{AD}$. Then, as long as the increased damping gain $K_{\mathrm{D}}$ does not lead to loss of the desired gain margin requirements $\left(G M_{1}<0 \mathrm{~dB}\right.$ and $\left.G M_{2}>0 \mathrm{~dB}\right)$, the system will be stable but with lower stability margin compared with the grid-side current control scheme without AD. 


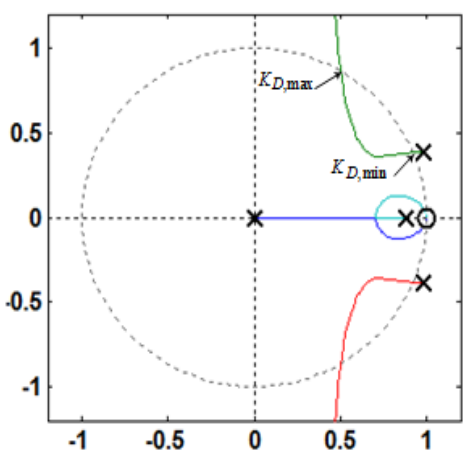

(a)

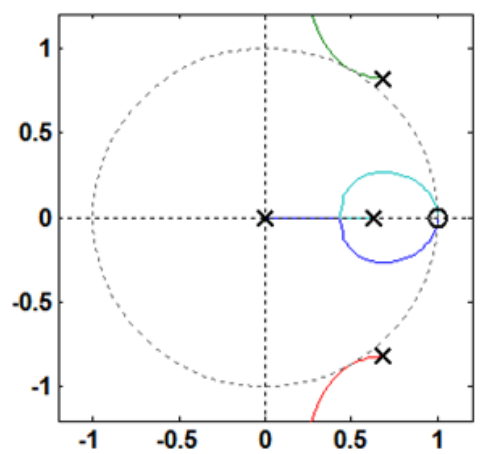

(b)

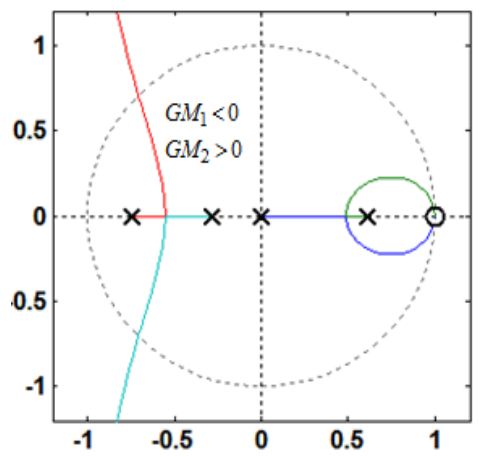

(c)

Figure 12. Root loci of the digital single-loop current control with proportional CCF AD method with variation of damping gain $K_{\mathrm{D}}$ for a fixed $K_{\mathrm{P}}$ value: (a) low resonant frequency region $\left(f_{\text {res }}<f_{\mathrm{s}} / 6\right.$; $\left.C_{\mathrm{f}}=36 \mu \mathrm{F} ; K_{\mathrm{P}}=0.0261\right) ;(\mathbf{b})$ critical resonant frequency $\left(f_{\text {res }}=f_{\mathrm{s}} / 6 ; C_{\mathrm{f}}=5 \mu \mathrm{F} ; K_{P}=0.07\right) ;$ and $(\mathbf{c})$ high resonant frequency region $\left(f_{\text {res }}>f_{\mathrm{s}} / 6 ; C_{\mathrm{f}}=1 \mu \mathrm{F} ; K_{\mathrm{p}}=0.116\right)$.

\subsection{Robustness Evaluation Against the Grid-Impedance Variation}

As shown previously, the digitally-controlled LCL-filtered grid-connected inverter with proportional CCF AD introduces the negative virtual resistance parallel with the filter capacitor for different resonance frequency regions and damping coefficients $\left(f_{\text {res }}<f_{\mathrm{s}} / 6\right.$ and $K_{\mathrm{D}}>K_{\mathrm{D}, \mathrm{C}}$ or $f_{\text {res }} \geq f_{\mathrm{s}} / 6$ and $K_{\mathrm{D}}>0$ ) due to the system delay effect. In this condition, a pair of open-loop unstable poles is generated and the closed-loop response will then have a non-minimum phase behavior [53]. Therefore, to ensure the system stability, the resonance frequency dependent stringent gain margin requirements need to be satisfied. For this reason, the system robustness against the grid inductance variation that commonly leads to the variation of resonance frequency $f_{\text {res, }}$ should be evaluated. The curves of gain margins $\left(G M_{1}\right.$ and $\left.G M_{2}\right)$ with the increase of $L_{g}$ are illustrated in Figure 13. From this Figure and the gain margin requirements discussed above, it can be concluded that if $f_{\text {res }}>f_{\mathrm{s}} / 6$ and $K_{\mathrm{D}}>0$, then, $G M_{1}<0 \mathrm{~dB}$ and $G M_{2}>0 \mathrm{~dB}$ are needed to ensure the system stability. However, with increasing $L_{\mathrm{g}}, G M_{1}$ increases, and $G M_{2}$ decreases. It leads to the smaller stability margin, which represents poor robustness against the variation of grid impedance [42]. If $f_{\text {res }}<f_{\mathrm{s}} / 6$ and $0<K_{\mathrm{D}} \leq K_{\mathrm{D}, \mathrm{C}}$, then, $G M_{1}>0 \mathrm{~dB}$ is needed to ensure stability. Moreover, if $f_{\text {res }}<f_{\mathrm{s}} / 6$ and $K_{\mathrm{D}}>K_{\mathrm{D}, \mathrm{C}}$, then, $G M_{1}>0 \mathrm{~dB}$ and $G M_{2}<0 \mathrm{~dB}$ are required. In both cases, with increase of $L_{\mathrm{g}}, G M_{1}$ increases, and $G M_{2}$ decreases (for $f_{\text {res }}^{\prime}>f_{\mathrm{s}} / 6$ ), which thus indicates the larger stability margin, and accordingly, high robustness against the variation of grid impedance [42]. Meanwhile, if $f_{\text {res }}=f_{\mathrm{s}} / 6$ and $K_{\mathrm{D}}>0$, it is needed to have $G M_{1}<0 \mathrm{~dB}$ and $G M_{2}>0 \mathrm{~dB}$. However, as seen in Figure 13 , in the situation that $G M_{1}=G M_{2}$, the system can hardly be stable regardless of $K_{\mathrm{D}}$ value [23,42].

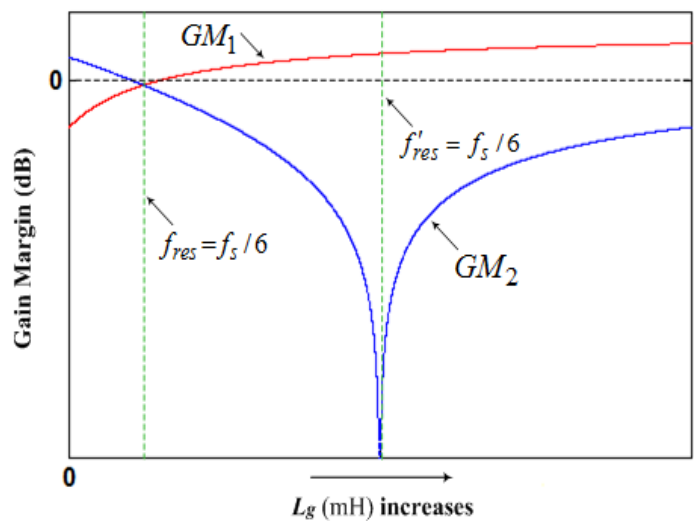

Figure 13. Curves of gain margins $\left(G M_{1}\right.$ and $\left.G M_{2}\right)$ with the increase of $L_{g}$. 


\subsection{Current Controller and Damping Gains Determination for Low Resonant Frequency Region}

As mentioned earlier and is clear from the root locus shown in Figure $6 c$, when the LCL filter resonant frequency is below the critical frequency $\left(\omega_{\text {res }}<\omega_{\text {crit }}\right)$, the single-loop grid-side current feedback control scheme needs an AD technique to achieve a stable system with minimal oscillation [23,42]. In this section, an enhanced procedure of current controller and damping gains determination is introduced. It ensures the stability, highest possible LCL damping and controller bandwidth, particularly taking system delay effect into account [23]. It should be noted that, control of optimum damping is important regarding stability, since the transient response of a system with an insufficient-damping will be seriously compromised when the system excited by a step change, whereas in an over-damped system, the system dynamic response and phase margin will strongly degrade [11]. Similar to the high frequency region, the current controller gains $\left(K_{\mathrm{p}}\right.$ and $\left.K_{\mathrm{i}}\right)$ can also be calculated using Equations (15) and (16), respectively, so that the gain crossover frequency is determined to obtain an appropriate phase margin, without any damping method, since the low-frequency characteristic of control plant will still be dominated by the series inductances [11]. However, by referring to the Bode phase plot in Figure 5a, it can be comfortably found that to avoid the rapid transition of transfer function phase (to yield satisfactory transient performance) and achieve a sufficient phase margin, the gain crossover frequency must be set enough below the LCL filter undamped resonance frequency $[11,23,42]$. Hence, the gain crossover frequency recommended in literature, $\omega_{\mathrm{gc}} \approx 0.3 \omega_{\text {res }}$, is considered in this frequency region in order to provide an acceptable system bandwidth [11,22]. Finally, for the low frequency resonance included in Table $1(625 \mathrm{~Hz})$, the controller gains are calculated using this strategy that gives the values of $K_{\mathrm{p}}=0.0261$ and $K_{\mathrm{i}}=3.075$. The frequency response for digital single-loop grid-side current feedback system in low frequency region has been already shown in Figure 5a.

As it is mentioned and is clear from Figure 12a, there are minimum and maximum values for damping gain $K_{\mathrm{D}}$ that ensures the resonant poles remain inside the unit circle to achieve maximum damping. This bounded range for $K_{\mathrm{D}}$ can then be determined by identifying some limitations. Accordingly, the maximum value of $K_{\mathrm{D}}$ can be obtained so that the magnitude of open-loop transfer function used in $z$-domain root locus analysis is equal to unity for a specific pole $z_{0}$ on the root locus, i.e.,

$$
\left|\frac{K_{\mathrm{D}} \times V_{\mathrm{DC}} \times G_{\mathrm{ic}}(z)}{z+K_{\mathrm{P}} \times V_{\mathrm{DC}} \times G_{i c}(z) \times G_{\mathrm{I}}(z)}\right|_{z=z_{0}}=1
$$

Note that by increase of the damping gain $K_{\mathrm{D}}$, the root loci path tracks through the unit circle at the critical resonant frequency $\omega_{\text {crit }}$ or $z=j \sqrt{3} / 2$ (Figure 12a). Therefore, by selecting the $z_{0}=0.5+j \sqrt{3} / 2$ and solving Equation (36) by some simple mathematical manipulations, $K_{\mathrm{D}, \max }$ can be found as Equation (37) [23]:

$$
K_{\mathrm{D}, \max }=\frac{\omega_{\text {res }} \times L_{1}}{V_{\mathrm{DC}} \times \sin \left(\omega_{\text {res }} T_{\mathrm{s}}\right)} \times\left|1-2 \cos \left(\omega_{\text {res }} T_{\mathrm{s}}\right)\right|+K_{\mathrm{P}} \times \zeta_{\mathrm{LC}}^{2} \times T_{\mathrm{s}}^{2}
$$

Using Routh's stability criterion used for a continuous time model in [60], $K_{\mathrm{D}, \min }$ to maintain the system stability can also be found for the discrete time model with delay [23]:

$$
K_{\mathrm{D}, \min } \geq \frac{K_{\mathrm{P}} \times L_{1}}{L_{1}+L_{2}+L_{\mathrm{g}}}
$$

As a result, in the low resonance frequency region, the allowable range is $0.013 \leq K_{\mathrm{D}} \leq 0.098$ in order to achieve an effective resonance stability control. Within this specified bounded range for $K_{D}$, using root locus poles placement approach, the maximum possible damping gain can be found, as seen in Figure 14a. Meanwhile, the bounded damping gain rang can also be determined by Jury stability criterion [50]. The Bode plot of Figure 14b indicates frequency response of the digital single-loop 
current control with proportional CCF AD method when the resonance frequency is significantly less than the sampling frequency for a fixed $K_{\mathrm{P}}$ and the maximum damping gain $K_{\mathrm{D}}$ values.

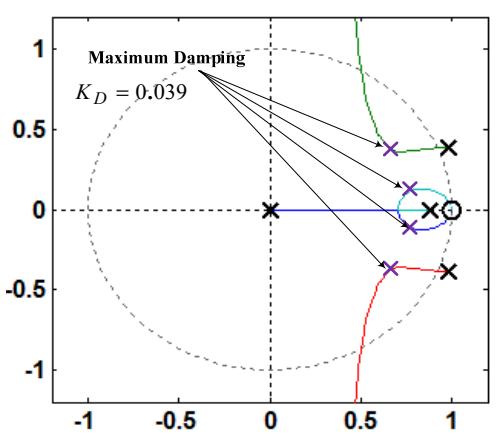

(a)

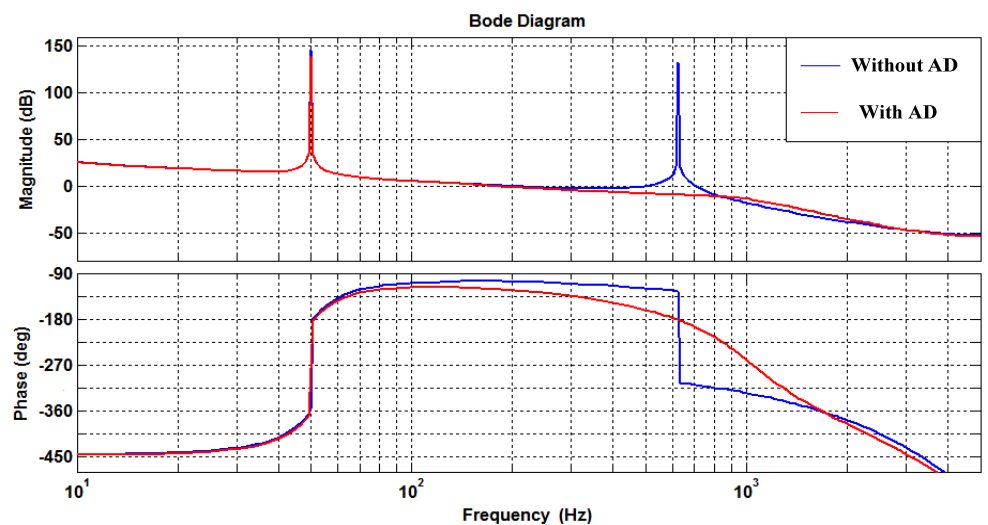

(b)

Figure 14. (a) Root locus maximum damping gain $K_{\mathrm{D}}$ selection; and (b) Bode plots. $\left(K_{\mathrm{P}}=0.0261\right.$, $\left.C_{\mathrm{f}}=36 \mu \mathrm{F}, K_{\mathrm{D}}=0.039\right)$.

As it is clear from the figure, incorporating proportional CCF AD in low resonance frequency region both suppresses the phase transition created in the case of without $\mathrm{AD}$ and reduces the resonance peak amplitude. Thus, as previously analyzed, this structure can be stabilized in low resonance frequency region with suitable proportional controller and damping gains.

In order to verify the theoretical findings and also to design current controller and select damping gains, the simulation results have been done with MATLAB/Simulink for a fully switched three-phase LCL-filtered inverter system, feeding into a stiff grid under ideal conditions without considering the winding resistance of the inductors and the equivalent series resistance of filter capacitor as well as the resistance component of grid impedance. Hence, simulation can be regarded to represent a worst case to control a well-damped system compared with a real system in practice that very small resistances are helping towards stability. The system parameters to test both low and high LCL resonant frequency regions are given in Table 1. Figure 15 shows simulation of system transient time-domain responses, where a step change of reference current from $4.4 \mathrm{~A}$ to $8.8 \mathrm{~A}$ is applied. As seen from Figure 15a, despite not using any $\mathrm{AD}$ method in the high resonance frequency region, there is no oscillation, even during the transient occurrence. This confirms that above the critical resonant frequency, appropriate setting the current controller parameters in single-loop control scheme without AD is sufficient to maintain stability and control the LCL filter resonance issue. However, as mentioned earlier, for a weak grid, where the grid impedance variation leads towide changes in LCL resonance frequency, system can easily become unstable if external damping solution is not employed. This could be due to the fact that the actual resonance frequency may be close to critical and low resonance frequency region $[26,42,46,53]$.

In contrast, Figure $15 \mathrm{~b}$ indicates the time response of the system under low LCL resonance frequency with enabling and disabling proportional CCF AD, where controller and damping gains set as previously discussed in Section 3.4. As it is clear from the figure, by applying the AD method $(t<2.1 \mathrm{~s})$, system is quite stable without resonance even during the transient event. In addition, if $\mathrm{AD}$ is disabled $(t>2.1 \mathrm{~s})$, large resonant currents appear and lead to instability of the system. Hence, for low resonant frequency region, $\mathrm{AD}$ is necessary to retain system stability and grid-side current quality. However, as previously proved theoretically, the proportional CCF AD is equivalent to the addition of a virtual impedance in parallel with the filter capacitor when computational and modulation delays are considered. The impacts identified from the virtual impedance can be included by filter resonance frequency shifting due to its imaginary part and a negative real part depending on the ratio of the 
filter resonance to control frequency [42,53]. It can unintentionally lead to a closed-loop non-minimum phase characteristic with unstable open-loop poles.

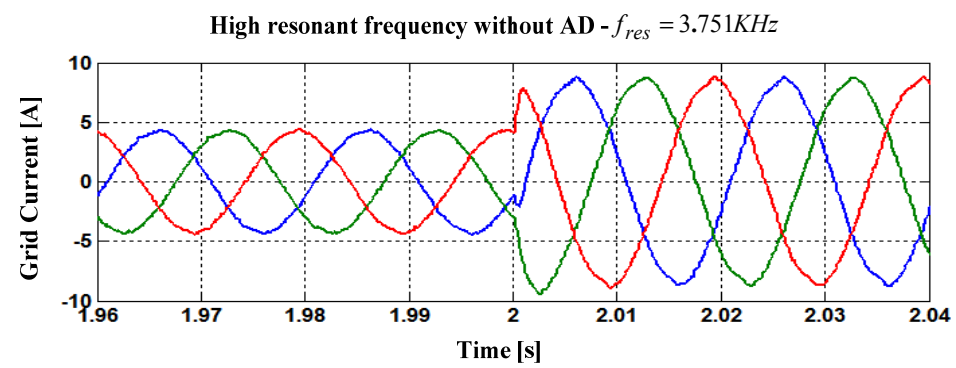

(a)

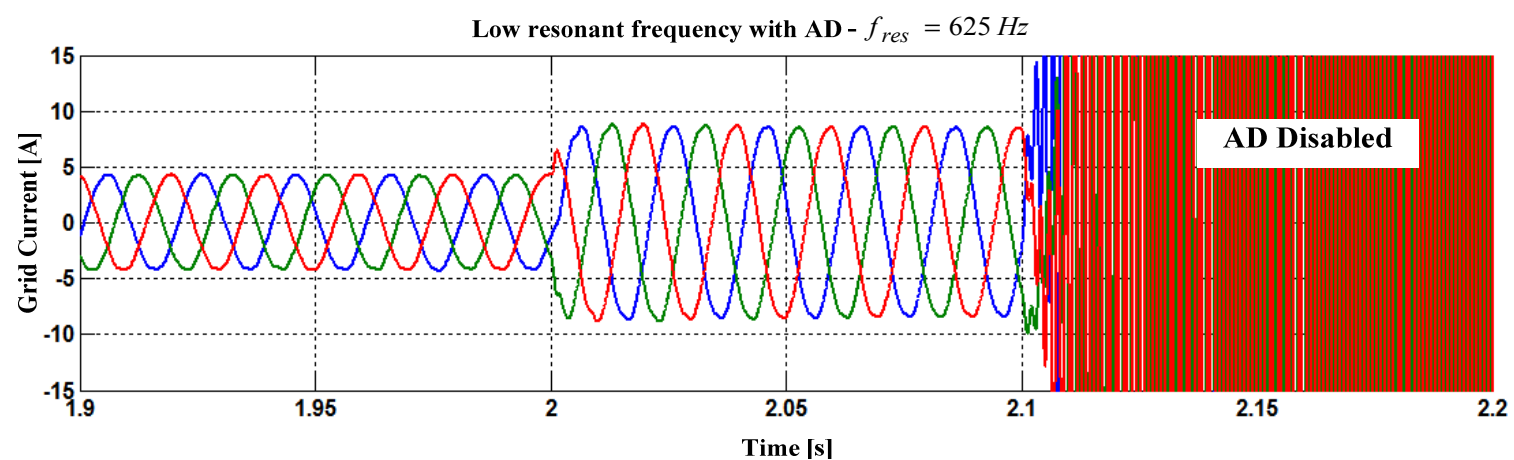

(b)

Figure 15. Simulation results of digitally-controlled LCL-filtered grid-connected inverter system: (a) high resonant frequency without $\mathrm{AD}\left(K_{\mathrm{P}}=0.116, K_{\mathrm{i}}=60.736, C_{\mathrm{f}}=1 \mu \mathrm{F}\right)$; and (b) low resonant frequency with enabling and disabling proportional capacitor feedback $\operatorname{AD}\left(K_{\mathrm{P}}=0.0261, K_{\mathrm{i}}=3.075\right.$, $\left.K_{\mathrm{D}}=0.039, C_{\mathrm{f}}=36 \mu \mathrm{F}\right)$.

Hence, in order to address these issues, improved CCF AD approaches should be provided so that the resonance stability performance is robustly maintained for all resonance frequencies against a wide variation in grid impedance. Two effective methods to cope with these problems will be presented in the next section.

\section{Improved Capacitor Current Feedback Active Damping Schemes}

To extend the valid damping region and ensure robustness against grid impedance variation, this section introduces the improved CCF AD methods. As was proven in the previous section, due to the effect of computation and PWM delays, the proportional CCF AD scheme is equivalent to frequency dependent virtual impedance, consisting of a resistor paralleled with a reactor, connected in parallel with the filter capacitor. The frequency dependent virtual resistor can damp the resonance peak of the LCL filter, whereas the resonance frequency is shifted by the embedded virtual reactor and grid-impedance variation. Obviously, by changing the resonance frequency, the damping performance will be affected. As clearly demonstrated by the open-loop Bode and root locus diagrams in the previous Section, if the actual resonance frequency is higher than the critical frequency of $f_{\mathrm{s}} / 6$, a pair of open-loop unstable poles appear due to the introduction of negative virtual resistor component in this frequency region. As a result, the LCL-filtered grid-connected inverter system can readily become unstable when the resonance frequency is close to critical frequency of $f_{\mathrm{s}} / 6$ due to the grid-impedance variation. Hence, the stability challenge for this critical resonance frequency must be resolved to acquire high robustness against the variation of grid impedance through the removal of open-loop unstable poles. 


\subsection{Capacitor Current Feedback Active Damping Based on First-Order High-Pass Filter}

Figure 16a shows the control block diagram of CCF AD scheme based on a first-order HPF [53] in $s$-domain, where $K_{\mathrm{D}}$ and $\omega_{\mathrm{D}}$ represent gain and cut-off frequency of the AD term, respectively. Corresponding filter equivalent circuits with and without considering delay effects, representing this AD method can also be seen in Figure $16 b, c$, respectively.

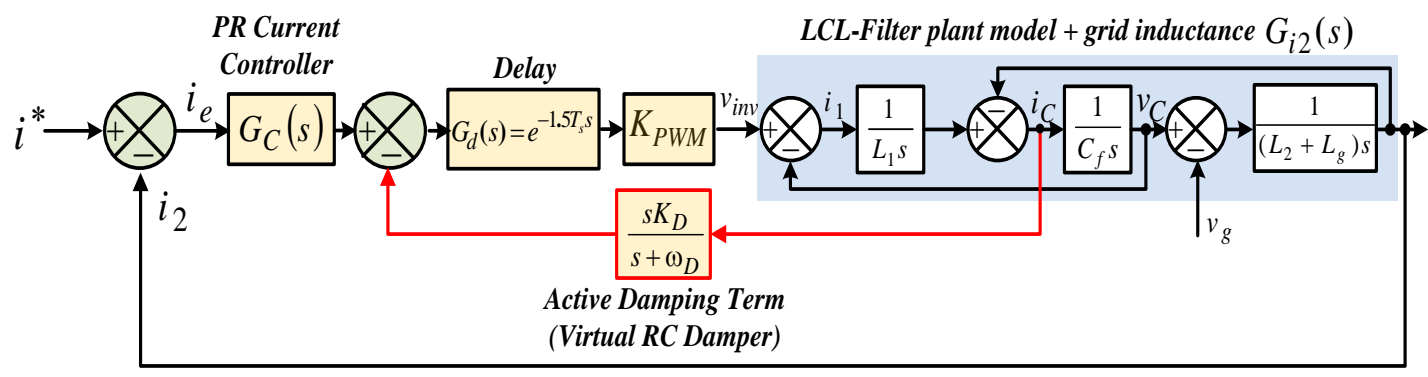

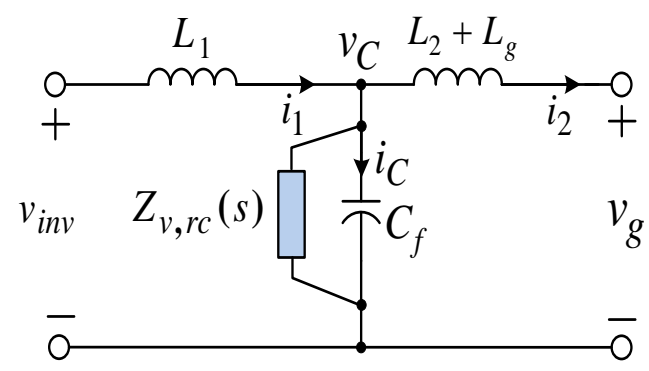

(b)

(a)

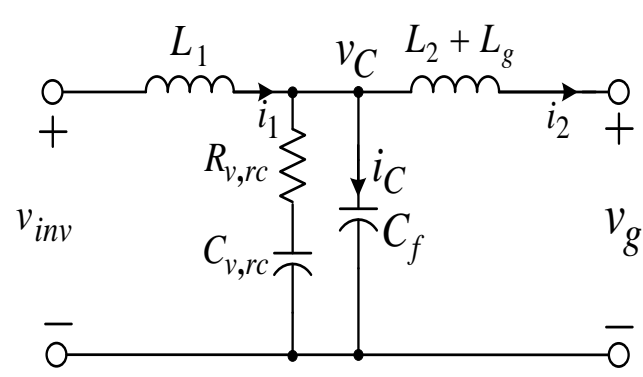

(c)

Figure 16. Block diagram and filter equivalent circuit for the first-order HPF-based CCF AD scheme: (a) control diagram representation; (b) filter equivalent circuit with delays considered; and (c) filter equivalent circuit without delays considered.

As it is clear from Figure 16c, if delays are overlooked, a virtual series RC damper can be specifically incorporated into the original filter plant with damper parameters derived as:

$$
R_{\mathrm{v}, \mathrm{rc}}=\frac{L_{1}}{C_{\mathrm{f}} \times K_{\mathrm{D}} \times K_{\mathrm{PWM}}}, C_{\mathrm{V}, \mathrm{rc}}=\frac{C_{\mathrm{f}} \times K_{\mathrm{D}} \times K_{\mathrm{PWM}}}{L_{1} \times \omega_{\mathrm{D}}}, \omega_{\mathrm{D}}=\frac{1}{R_{\mathrm{V}, \mathrm{rc}} \times C_{\mathrm{V}, \mathrm{rc}}}
$$

After considering delays and using Euler's formula, these expressions change to Equation (40):

$$
\begin{gathered}
Z_{\mathrm{v}, \mathrm{rc}}(j \omega)=\frac{L_{1}}{C_{\mathrm{f}} \times K_{\mathrm{D}} \times K_{\mathrm{PWM}}} \times\left(1-j \frac{\omega_{\mathrm{D}}}{\omega}\right)\left[\cos \left(1.5 \omega T_{\mathrm{S}}\right)+j \sin \left(1.5 \omega T_{\mathrm{S}}\right)\right] \\
\operatorname{Re}\left\{Z_{\mathrm{v}, \mathrm{rc}}(j \omega)\right\}=R_{\mathrm{v}, \mathrm{rc}} \times \cos \left(1.5 \omega T_{\mathrm{S}}\right)+\frac{1}{\omega \times C_{\mathrm{v}, \mathrm{rc}}} \times \sin \left(1.5 \omega T_{\mathrm{S}}\right) \\
\operatorname{Im}\left\{Z_{\mathrm{v}, \mathrm{rc}}(j \omega)\right\}=R_{\mathrm{v}, \mathrm{rc}} \times \sin \left(1.5 \omega T_{\mathrm{S}}\right)-\frac{1}{\omega \times C_{\mathrm{v}, \mathrm{rc}}} \times \cos \left(1.5 \omega T_{\mathrm{S}}\right)
\end{gathered}
$$

Unlike, the proportional CCF AD scheme in Equation (23), the real and imaginary parts of Equation (40) have an additional term, which are adjustable by $C_{\mathrm{v}, \mathrm{rc}}$ and can be useful to lessen the likelihood that $\operatorname{Re}\left\{Z_{\mathrm{v}, \mathrm{rc}}(j \omega)\right\}$ becomes negative. With this understanding, the critical frequency $\omega_{\mathrm{nR}}$, wherein $\operatorname{Re}\left\{Z_{\mathrm{v}, \mathrm{rc}}(j \omega)\right\}$ in Equation (40) becomes negative, can be limited in accordance with Equation (41) in terms of the sampling frequency when $\omega_{\mathrm{D}}$ increases, as $\omega_{\mathrm{nR}}=\omega_{\mathrm{s}} / 3$ (Figure 17):

$$
\operatorname{Re}\left\{Z_{\mathrm{v}, \mathrm{rc}}(j \omega)\right\}=0 \Rightarrow \frac{\omega_{\mathrm{nR}}}{\omega_{\mathrm{s}}} \times \cos \left(3 \pi \frac{\omega_{\mathrm{nR}}}{\omega_{\mathrm{s}}}\right)+\frac{\omega_{\mathrm{D}}}{\omega_{\mathrm{s}}} \times \sin \left(3 \pi \frac{\omega_{\mathrm{nR}}}{\omega_{\mathrm{s}}}\right)=0
$$


where $\omega_{\mathrm{s}}=2 \pi f_{\mathrm{s}}$. Compared to the proportional CCF AD scheme, compensation of the delay-induced phase lag can be achieved by the added HPF resulting from extension of the critical frequency from $f_{\mathrm{s}} / 6$ to $f_{\mathrm{s}} / 3$ [53]. This means that $\operatorname{Re}\left\{Z_{\mathrm{v}, \mathrm{rc}}(j \omega)\right\}$ is less likely to be negative. However, this resulting improvement is not limitless, since if LCL resonance frequency of a system placed between $f_{\mathrm{s}} / 3$ and $f_{\mathrm{s}} / 2$ (Nyquist frequency), the closed-loop response has always a non-minimum phase behavior.

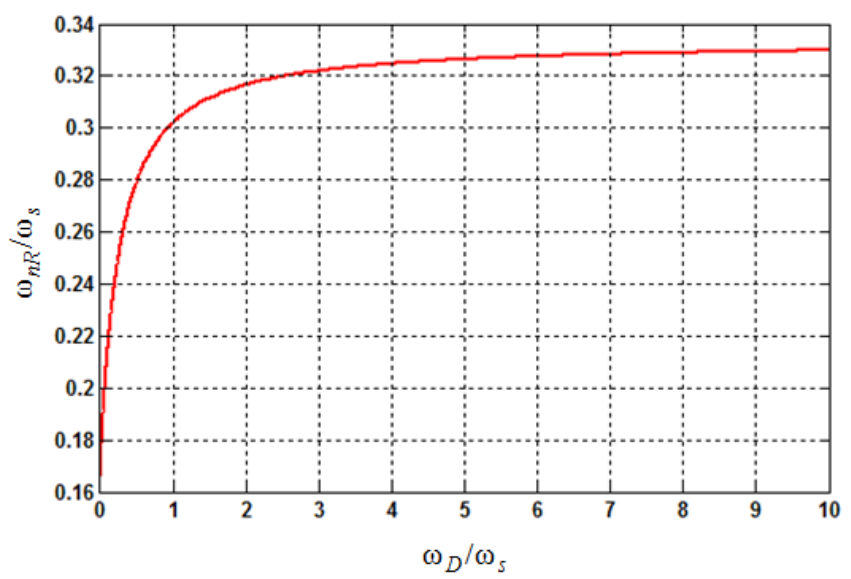

Figure 17. Relationship between $\omega_{\mathrm{nR}}$ and $\omega_{\mathrm{D}}$.

Parameter Tunning, Stability Analysis, and Robustness Evaluation against Grid Impedance Variation

For system design and stability analysis as well as robustness evaluation against grid impedance variation, $z$-domain frequency response and root locus analysis are performed based on the control scheme in Figure 18, which is z-domain block diagram of Figure 16a.

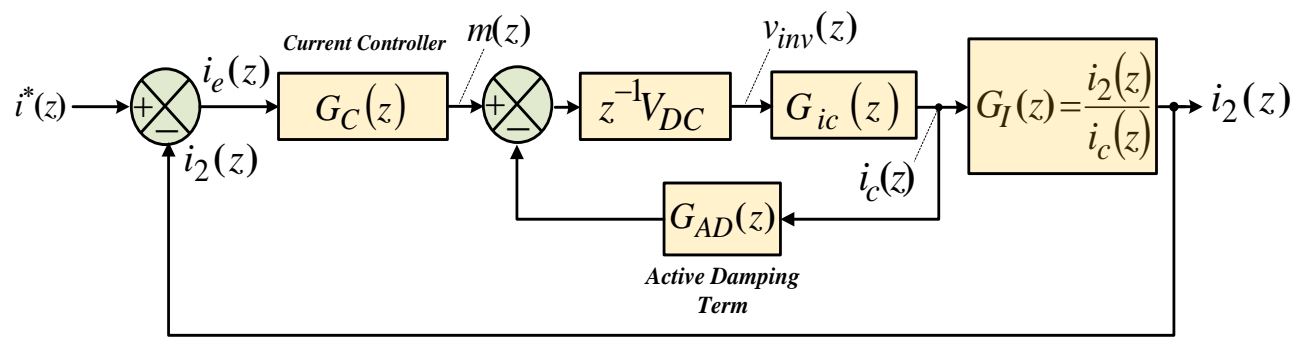

Figure 18. Z-domain block diagram of the first-order HPF-based CCF AD scheme.

The HPF used for AD term (virtual RC damper) can be discretized by Tustin approximation [50] as follows:

$$
G_{\mathrm{AD}}(z)=\frac{2 K_{\mathrm{D}} \times(z-1)}{\left(\omega_{\mathrm{D}} T_{\mathrm{s}}+2\right) z+\left(\omega_{\mathrm{D}} T_{\mathrm{s}}-2\right)}
$$

Combining Equations (4), (27), (28) and (42), the open-loop gain transfer function for the scheme shown in Figure 18 is readily achieved as:

$$
G_{\text {open_loop }}(z)=\frac{i_{2}(z)}{i_{\mathrm{e}}(z)}=\frac{V_{\mathrm{DC}} \times G_{\mathrm{C}}(z) \times G_{\mathrm{I}}(z) \times G_{i \mathrm{c}}(z)}{z+V_{\mathrm{DC}} \times G_{i \mathrm{c}}(z) \times G_{\mathrm{AD}}(z)}
$$

Then, according to Equation (43), the characteristic equation for this $\mathrm{AD}$ control scheme can be written as:

$$
z+K_{\mathrm{D}} \times V_{\mathrm{DC}} \times G_{i \mathrm{c}}(z) \times G_{\mathrm{AD}}^{\prime}(z)+K_{\mathrm{P}} \times V_{\mathrm{DC}} \times G_{i \mathrm{c}}(z) \times G_{\mathrm{I}}(z)=0
$$

where $G_{\mathrm{AD}}^{\prime}(z)$ has the same equation as Equation (42), excluding $K_{\mathrm{D}}$. 
Figure 19 shows the closed-loop poles movement of the control scheme with variation of the HPF gain $K_{\mathrm{D}}$, where HPF cut-off frequency $\omega_{\mathrm{D}}$ is swept from 0 to $0.8 \omega_{\mathrm{s}}$ with a step of $0.2 \omega_{\mathrm{S}}$ as also controller gains are designed based on the algorithms adopted in Sections 2.2 and 3.4, respectively, for low and high resonance frequency regions. To assess robustness subject to wide impedance variation, assuming a fixed value for the filter capacitor $\left(C_{\mathrm{f}}=4.7 \mu \mathrm{F}\right)$, three grid inductance values are considered that represent low and high LCL resonance frequency regions around the critical frequency of $f_{\mathrm{s}} / 6=1.67 \mathrm{kHz}$.

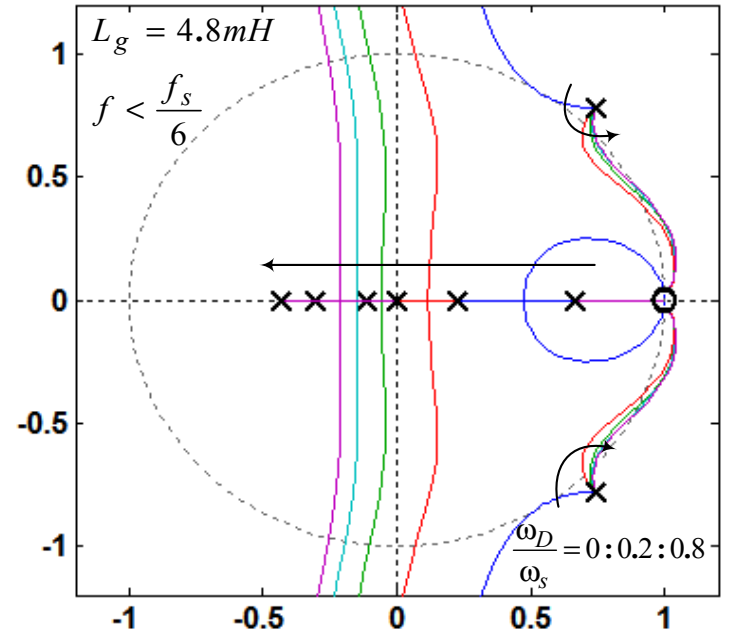

(a)

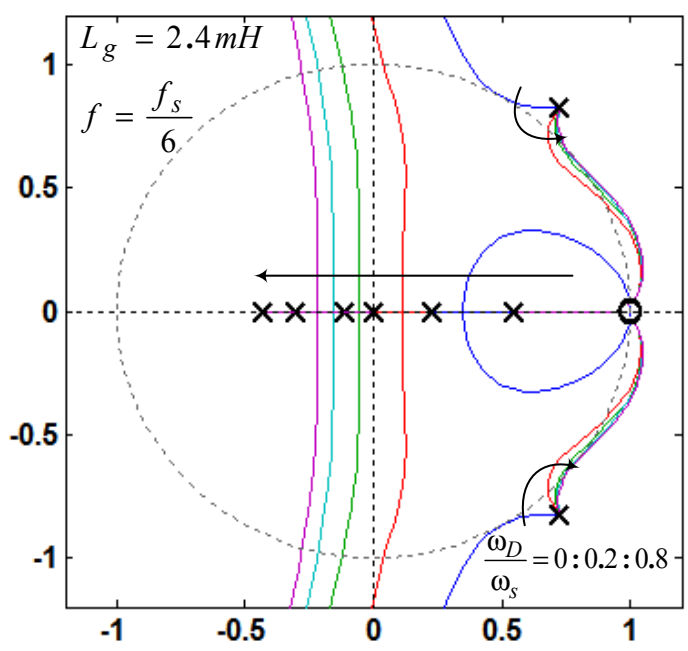

(b)

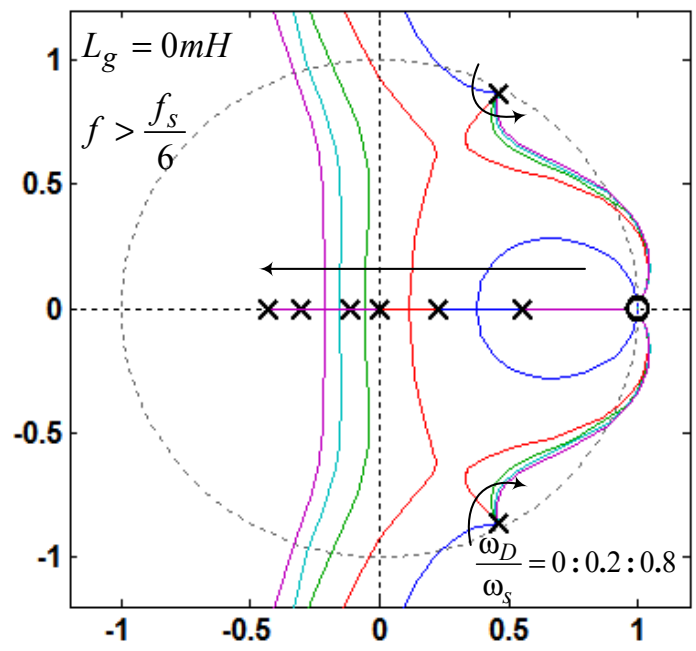

(c)

Figure 19. Root loci of the grid-side current control with and without CCF AD scheme for different grid inductances: (a) $L_{\mathrm{g}}=4.8 \mathrm{mH}, f_{\text {res }}=1.521 \mathrm{kHz}, K_{\mathrm{P}}=0.09, K_{\mathrm{i}}=25.8$ (low resonant frequency region); (b) $L_{\mathrm{g}}=2.4 \mathrm{mH}, f_{\text {res }}=1.667 \mathrm{kHz}, K_{\mathrm{P}}=0.09, K_{\mathrm{i}}=25.8$ (critical resonant frequency); and (c) $L_{\mathrm{g}}=0 \mathrm{mH}$, $f_{\text {res }}=2.119 \mathrm{kHz}, K_{\mathrm{P}}=0.06, K_{\mathrm{i}}=26.5$ (high resonant frequency region).

As seen in Figure 19a,b, due to the lack of inherent damping effect, as explained in the previous section, when the LCL resonance frequency is below or equal to critical resonance frequency, the resonant poles initially are out of the unit circle, and hence, the system will be unstable without AD. It should be noted that applying the proportional CCF $\mathrm{AD}\left(\omega_{\mathrm{D}}=0\right)$ can only lead to the resonant poles touching the unit circle, but never entering the circle. Therefore, for this resonance frequency and this type of $\mathrm{AD}$ method, the system will always be unstable irrespective of the damping gain that is applied (blue line in Figure 19b). However, in this case, the poles will track back inside the unit 
circle by applying the HPF-based CCF AD method, and hence, the stability will be established. Note that in these resonance frequencies, the stability would be jeopardized by increasing the HPF cut-off frequency $\omega_{\mathrm{D}}$ (Figure 19a,b). In contrast, when the LCL resonance frequency is above the critical frequency $\left(L_{\mathrm{g}}=0 \mathrm{mH}\right)$, the resonant poles initially are inside the unit circle because of the inherent resonance damping effect (Figure 19c). However, too large HPF gain will force the poles track back outside the unit circle, and lead to the system instability.

Generally speaking, the design of HPF parameters should firstly be attempted by selecting a proper $\omega_{\mathrm{D}}$ that will give an appropriate margin between resonance frequency and $\omega_{\mathrm{nR}}$ according to Figure 17. Then, based on the root locus plots illustrated in Figure 19, the appropriate $K_{\mathrm{D}}$ can be selected [53].

To further understand effectiveness of the HPF-based CCF AD, comparison among the different control cases is performed in the frequency domain (Figure 20). As seen in Figure 20, in the case of without $\mathrm{AD}$, the system is very sensitive to the variation of grid impedance, so that it will be unstable when the resonance frequency decreases below $f_{\mathrm{s}} / 6$ and also can be stabilized by proper selection of proportional controller gain when the resonance frequency increases above $f_{\mathrm{s}} / 6$. By applying the proportional CCF AD, as explained, a non-minimum phase behavior (the presence of open-loop unstable poles) occurs due to the inserted negative virtual resistance (Figure 20). After introducing the HPF-based CCF AD, as it is clear from Figure 20, the behavior of system non-minimum phase has been mitigated by the embedded virtual capacitor in the HPF $[23,26,42,46,53]$. For more details regarding the stability conditions, please, refer to the explanations provided for Figure 10 in Section 3.2. Thus, based on these observations prove effectiveness of the HPF-based CCF AD scheme because of extension the damping region from $\left(0, f_{\mathrm{s}} / 6\right)$ to $\left(0, f_{\mathrm{s}} / 3\right)$ through proper selection of the HPF parameters [53].

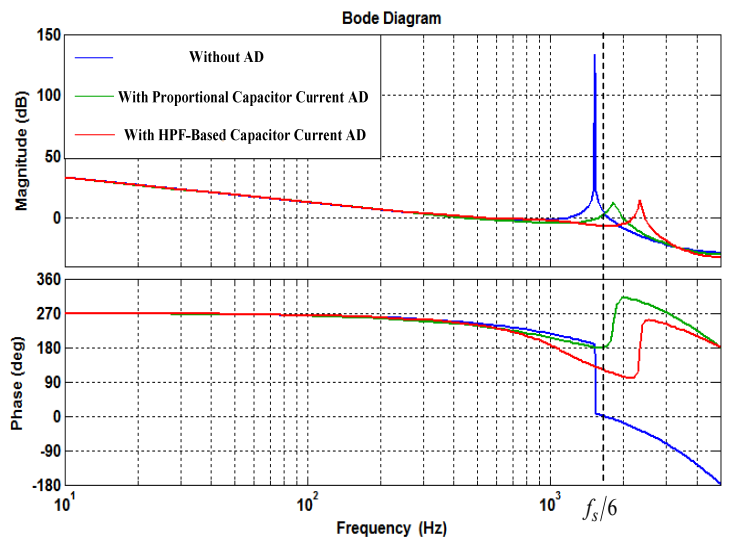

(a)

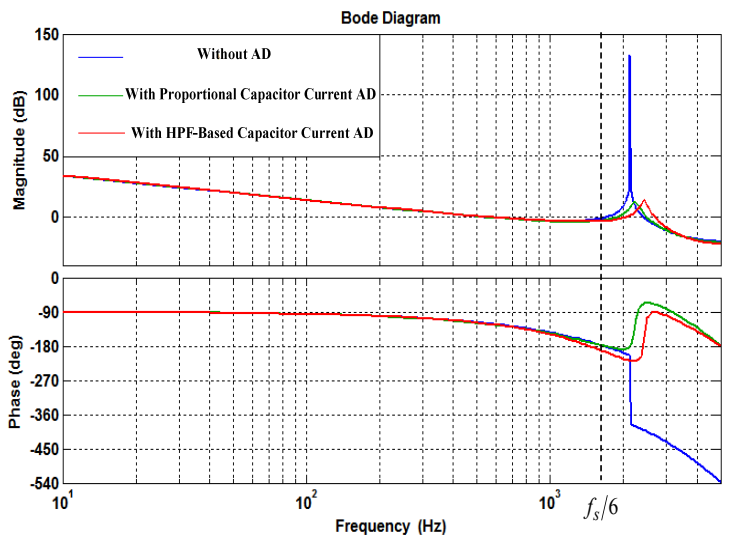

(b)

Figure 20. Bode plots showing open-loop gain of grid-side current control with and without AD schemes: (a) low frequency region $\left(L_{\mathrm{g}}=4.8 \mathrm{mH}, f_{\text {res }}=1.521 \mathrm{kHz}, K_{\mathrm{P}}=0.09, K_{\mathrm{D}}=0.041\right.$ (green diagram), $K_{\mathrm{D}}=0.115$ (red diagram)); and (b) high resonant frequency $\left(L_{\mathrm{g}}=0 \mathrm{mH}, f_{\text {res }}=2.119 \mathrm{kHz}, K_{\mathrm{P}}=0.06\right.$, $K_{\mathrm{D}}=0.02$ (green diagram), $K_{\mathrm{D}}=0.055$ (red diagram)).

\subsection{Capacitor Current Feedback Active Damping with Reduced Computation Delay}

To remove the open-loop unstable poles (mitigation of the non-minimum phase characteristic) and widen the effective damping region, a CCF AD method with reduced computation delay has been presented in [42], which is realized by shifting the capacitor current sampling instant towards PWM reference update instant. Using this model-independent method, as will be shown later, the embedded virtual impedance is formed in a wider frequency range more like a resistor; thus, high robustness against the variation of grid impedance is obtained. Since the fundamental component of the capacitor current has no contribution in resonance damping performance, the capacitor current can be sampled 
before the PWM reference update instant [42]. To this end, the capacitor current is sampled at the time instant of $\lambda T_{\mathrm{s}}(0<\lambda<1)$.

Figure 21a indicates the control block diagram of CCF AD with reduced computation delay scheme in s-domain. Corresponding filter equivalent circuit by applying this AD method can also be seen in Figure 21b. As it is clear in Figure 21b, a virtual parallel $R L$ damper can be specifically incorporated into the original filter plant with damper parameters derived as:

$$
\begin{aligned}
& Z_{\mathrm{v}}(j \omega)=R_{\mathrm{eq}}(\omega) \| j X_{\mathrm{eq}}(\omega) \\
& R_{\mathrm{eq}}(\omega)=\frac{L_{1}}{C_{\mathrm{f}} \times K_{\mathrm{D}} \times K_{\mathrm{PWM}} \times \cos \left((\lambda+0.5) \times \omega T_{\mathrm{s}}\right)}, X_{\mathrm{eq}}(\omega)=\frac{L_{1}}{C_{\mathrm{f}} \times K_{\mathrm{D}} \times K_{\mathrm{PWM}} \times \sin \left((\lambda+0.5) \times \omega T_{\mathrm{s}}\right)}
\end{aligned}
$$

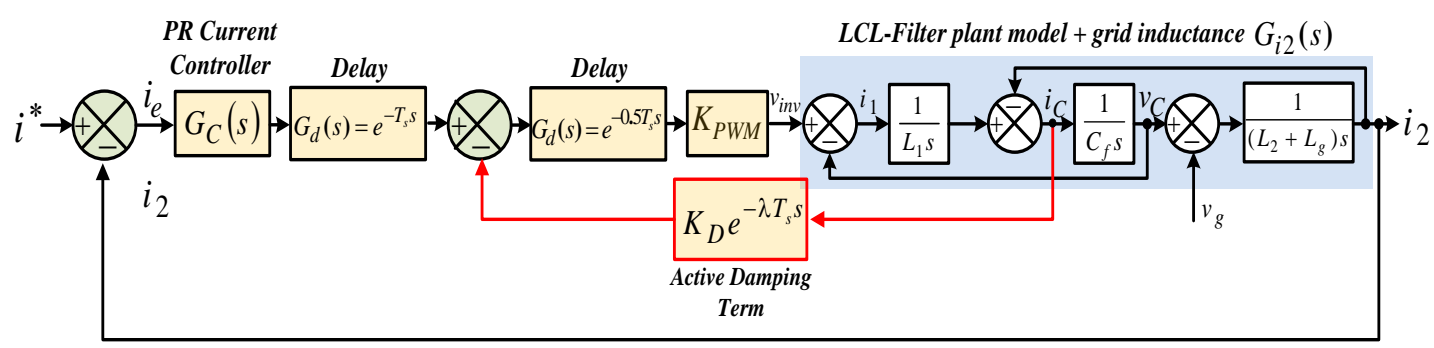

(a)

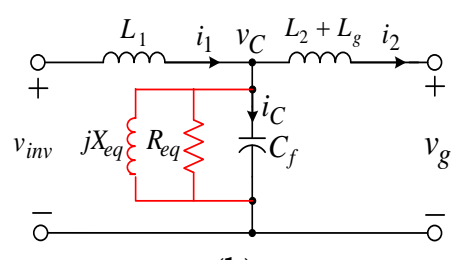

(b)

Figure 21. Block diagram and filter equivalent circuit of the digitally controlled LCL-filtered grid-connected inverter with the improved CCF AD scheme by reduced computation delay: (a) control diagram representation; and (b) filter equivalent circuit.

Based on Equation (45), it is clear that both $R_{\mathrm{eq}}$ and $X_{\mathrm{eq}}$, which are frequency dependent, can be positive or negative. The boundary of frequency that $R_{\mathrm{eq}}$ and $X_{\mathrm{eq}}$ are positive or negative, as shown in Figure 22, is dependent on $\lambda$ and can be respectively derived and denoted as follows:

$$
\begin{aligned}
& f_{\mathrm{R}}=\frac{f_{\mathrm{s}}}{4(\lambda+0.5)} \\
& f_{\mathrm{X}}=\frac{f_{\mathrm{s}}}{2(\lambda+0.5)}
\end{aligned}
$$

Obviously, for the $\lambda=1$ (synchronous sampling scheme), $f_{\mathrm{R}}=f_{\mathrm{s}} / 6, f_{\mathrm{X}}=f_{\mathrm{s}} / 3$, which discussed previously in Section 3. In Figure 22 and Equation (46), it can be observed that compared with the synchronous sampling scheme, reduction of computation delay by shifting the capacitor current sampling instant $(0<\lambda<1)$ causes increase in the frequency range in which the $R_{\text {eq }}$ is positive $\left(f_{\mathrm{s}} / 6<f_{\mathrm{R}}<f_{\mathrm{s}} / 2\right)$. In addition, with a smaller $\lambda$, the virtual impedance behaves more like the virtual resistor. According to the analysis presented in Section 3, it can be well found that to get rid of the open-loop unstable poles; $f_{\mathrm{R}}$ should be higher than $f_{\text {res }}$ [42]. Therefore, for the high LCL-filter resonant frequencies, a smaller $\lambda$ would be preferable. Clearly, the ideal case can be achieve when $\lambda=0$. However in practice, $\lambda$ is not necessarily so small since it is chosen based on a specific $f_{\text {res }}$ that usually constrained by the harmonic attenuation requirements [40]. Thus, for $f_{\text {res }}<f_{\mathrm{s}} / 4$, a positive $R_{\mathrm{eq}}$ in the range $\left(0, f_{\mathrm{s}} / 4\right)$ is desirable, which can be obtained by choosing $\lambda=0.5$ (Figure 22b). This case is 
considered in the following section to show how the damping performance is improved by reducing the computation delay.

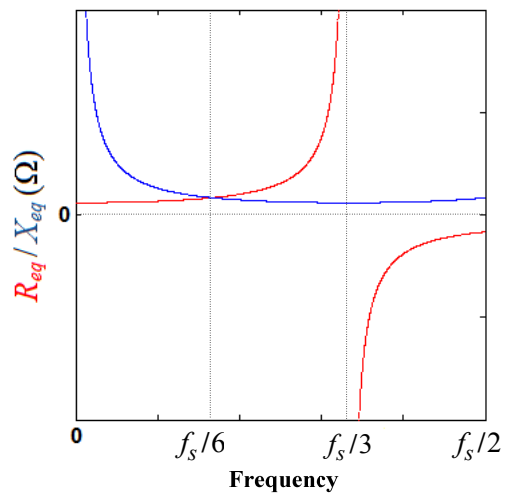

(a)

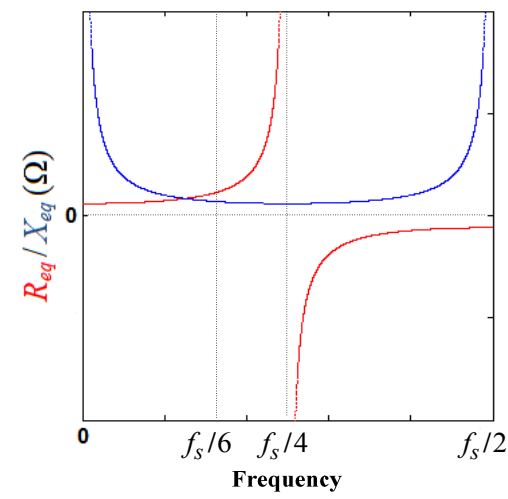

(b)

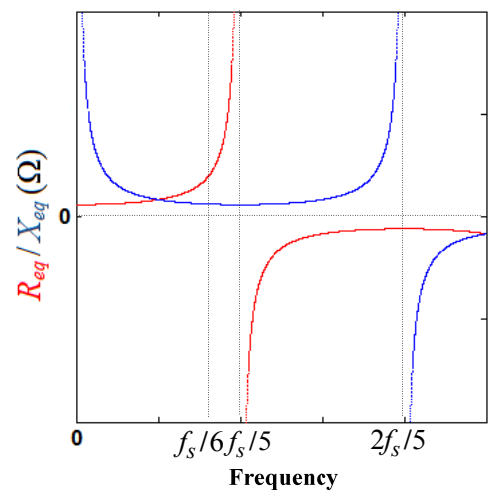

(c)

Figure 22. Curves of $R_{\mathrm{eq}}$ and $X_{\mathrm{eq}}$ as the function of frequency: (a) $\lambda=0.25 ;(\mathbf{b}) \lambda=0.5$; and (c) $\lambda=0.75$.

Performance of Resonance Damping with Reduced Computation Delay

To evaluate performance of resonance damping with reduced computation delay, the open-loop gain expression of Figure 21a is required, which is given as Equation (48) in z-domain:

$$
G_{\text {open_loop }}(z)=\frac{i_{2}(z)}{i_{e}(z)}=\frac{z^{-1} V_{\mathrm{DC}} \times G_{\mathrm{C}}(z) \times G_{\mathrm{I}}(z) \times G_{i \mathrm{c}}(z)}{1+V_{\mathrm{DC}} \times K_{\mathrm{D}} \times Z_{\mathrm{ZOH}}\left[G_{i \mathrm{c}}(s) \times \mathrm{e}^{-\lambda T_{\mathrm{s}} s}\right]}
$$

where:

$$
\mathrm{Z}_{\mathrm{ZOH}}\left[G_{i \mathrm{c}}(s) \mathrm{e}^{-\lambda T_{\mathrm{s}} s}\right]=\frac{z-1}{\omega_{\text {res }} \times L_{1}} \times \frac{z \sin \left((1-\lambda) \times \omega_{\text {res }} T_{\mathrm{s}}\right)+\sin \left(\lambda \omega_{\text {res }} T_{\mathrm{s}}\right)}{z\left(z^{2}-2 z \cos \left(\omega_{\text {res }} T_{\mathrm{s}}\right)+1\right)}
$$

In addition, the open-loop gain (inner proportional CCF loop only) for this AD control scheme can be obtained as:

$$
1+K_{\mathrm{D}} \times V_{\mathrm{DC}} \times Z_{\mathrm{ZOH}}\left[G_{i \mathrm{c}}(s) \times \mathrm{e}^{-\lambda T_{\mathrm{s}} s}\right]=0
$$

Figure 23 illustrates stability analysis of the CCF AD with reduced computation delay based on the Bode diagrams of the open-loop gain $G_{\text {open_loop }}(z)$ and root loci of the inner proportional CCF only for frequency range of $\left(f_{\text {res }}<f_{\mathrm{s}} / 4\right)$. As shown in Figure 23a and is clear from Equation (45), in the range $\left(0, f_{\mathrm{s}} / 2\right)$, with increase of the $K_{\mathrm{D}}$, a higher actual resonance frequency $f_{\text {res }}^{\prime}$ is generated. Since the frequency boundary of $X_{\text {eq }}$ is $f_{\mathrm{s}} / 2$ (Figure $22 \mathrm{~b}$ ), $f_{\text {res }}^{\prime}$ will only approach to $f_{\mathrm{s}} / 2$ but never step over it. Also, it can be seen from Figure 23b that how the resonant poles track inside unit circle for $f_{\text {res }}<f_{\mathrm{s}} / 4$ to make a damping contribution unless too large damping gain $K_{\mathrm{D}}$ is applied (Figure 23b). Obviously, there is a maximum useful damping gain, beyond which the stability of overall system will be compromised. This value can be obtained so that the magnitude of the transfer function used in root locus analysis is equal to unity for a specific pole $z_{0}=j$ on the root locus, i.e.,

$$
\left|K_{\mathrm{D}} \times V_{\mathrm{DC}} \times Z_{\mathrm{ZOH}}\left[G_{i \mathrm{c}}(z) \times \mathrm{e}^{-\lambda T_{\mathrm{s}} s}\right]\right|_{z=z_{0}}=1
$$

By solving Equation (51), $K_{\mathrm{D}, \mathrm{m}}$ can be found as Equation (52) [42]:

$$
K_{\mathrm{D}, \mathrm{m}}=\frac{\omega_{\text {res }} \times L_{1} \times \cos \left(\omega_{\mathrm{res}} T_{\mathrm{s}}\right)}{V_{\mathrm{DC}} \times \sin \left(0.5 \omega_{\mathrm{res}} T_{\mathrm{s}}\right)}
$$

If $f_{\text {res }}<f_{\mathrm{s}} / 4$ and $0<K_{\mathrm{D}}<K_{\mathrm{D}, \mathrm{m}}$, i.e., $f_{\text {res }}^{\prime}<f_{\mathrm{s}} / 4$, then $R_{\text {eq }}$ is positive at $f_{\text {res }}^{\prime}$ (Figure 22b), and no open-loop unstable pole exists, as seen in Figure 23b. Hence, the phase plot crosses over $-180^{\circ}$ only at $f_{\text {res }}$ in the direction of phase decrease as shown in Figure 23a. In addition, if $f_{\text {res }}<f_{\mathrm{s}} / 4$ and 
$K_{\mathrm{D}}=K_{\mathrm{D}, \mathrm{m}}$, i.e., $f_{\text {res }}^{\prime}=f_{\mathrm{s}} / 4$, then $R_{\mathrm{eq}}$ is infinite at $f_{\text {res }}^{\prime}$ (Figure $22 \mathrm{~b}$ ), and no open-loop unstable pole exists, as seen in Figure 23b. In this case, it has no contribution to the resonance damping performance, and the phase plot also crosses over $-180^{\circ}$ only at $f_{\text {res }}$ in the direction of phase decrease (Figure $23 a$ ). Based on the Nyquist stability criterion [50], to ensure the system stability, the value of 2( $\left.N^{+}-N^{-}\right)$will be equal to the number of the open-loop unstable poles, as long as the gain margin at $-180^{\circ}$ crossover frequency $\left(f_{\text {res }}\right)$ is greater than $0 \mathrm{~dB}$. Obviously, these findings are exactly the same as the case of $f_{\text {res }}^{\prime}<f_{\mathrm{s}} / 6$ in conventional proportional CCF AD scheme with the synchronous sampling condition $(\lambda=1)$. For more details regarding the stability conditions, please, refer to the explanations provided for Figure 10 in Section 3.2 It can be found that a robust damping performance will be achieved using this control method for $f_{\text {res }}^{\prime}=f_{\mathrm{s}} / 4$ with $\lambda=0.5$.

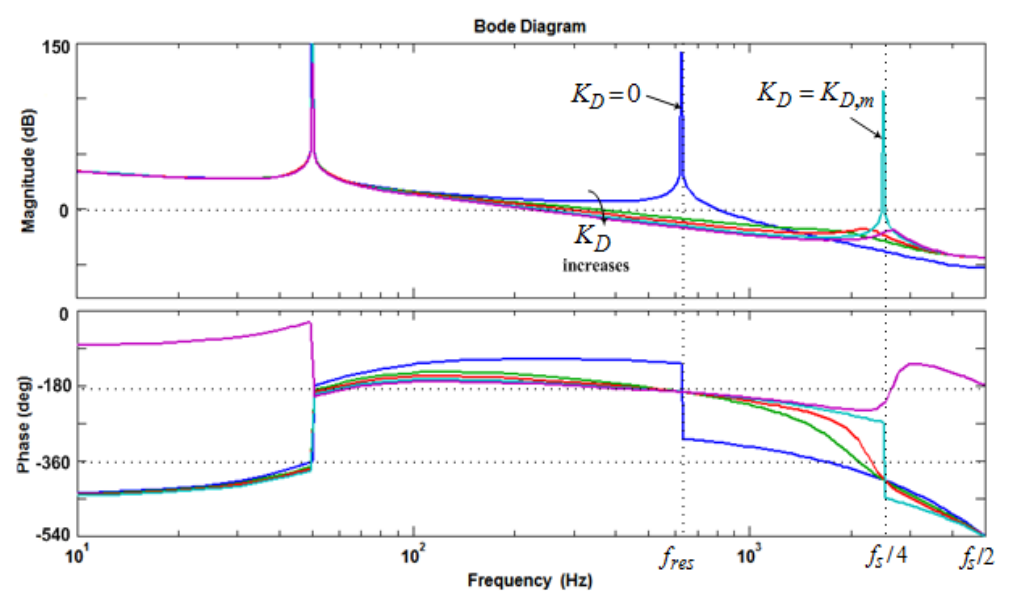

(a)

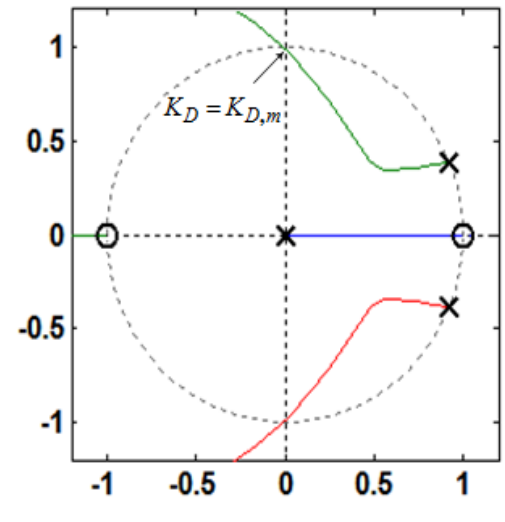

(b)

Figure 23. Stability analysis of the CCF AD with reduced computation delay. (a) Bode plotsof the open-loop gain; and (b) root loci of the inner proportional CCF only. $\left(f_{\text {res }}<f_{\mathrm{s}} / 6 ; C_{\mathrm{f}}=36 \mu \mathrm{F}\right.$; $\left.K_{\mathrm{p}}=0.0261 ; K_{\mathrm{i}}=3.0769\right)$.

In general, using this method, the open-loop unstable poles are removed and with achieving a stable operation even for the resonance frequency of $f_{\mathrm{s}} / 6$, high damping robustness against the variation of grid impedance is acquired. However, since the capacitor current includes abundant switching ripples, aliasing might happen if the sampling instant is not properly determined. Therefore, before applying this damping control structure in practice, a detailed investigation on the sampling-induced aliasing should be provided. It is demonstrated in [42] that aliased harmonics in the capacitor current sampling are mainly low-order harmonics. However, given that the LCL-filter resonance appears in the high-frequency range, these low-frequency harmonics will not affect the resonance damping performance, and only might affect the tracking performance of grid current reference. Fortunately these undesirable effects can be suppressed through the current controller with high low-frequency gains. Also, Pan et al. [42] suggested that for $\lambda \leq 0.1$ and $\lambda=0.5$, the minimum harmonic contents exist in the capacitor current sampling. Note that in practice, the selected value of $\lambda$ is related to the A/D converter and the Digital Signal Processor (DSP) that employed. Another important implementation issue in the capacitor current sampling is the switching noise. To overcome this shortcoming, a low-pass filter with a proper cutoff frequency can be installed between the current sensor and the A/D converter. It is noteworthy that for the delay reduction, the computation delay can also be compensated with a lead compensator [15]. However, it causes the amplification of high-frequency noise [42]. 


\section{Conclusions}

This paper has presented a comprehensive investigation and complete theoretical analysis of the digitally controlled LCL-filtered grid-connected inverter with CCF AD approaches, including sample and PWM transport delay. At first, using a detailed discrete-time stability analysis for single-loop grid-side current control scheme under various resonance frequencies without any damping method and with considering the PWM transport delay effect, three controller operation regions have been identified. These include a low resonance frequency region $\left(f_{\text {res }}<f_{\mathrm{s}} / 6\right)$ where $\mathrm{AD}$ is obligatory in order to damp the LCL resonance and retain closed-loop system stability, a high resonance frequency region $\left(f_{\text {res }}>f_{\mathrm{s}} / 6\right)$ where $\mathrm{AD}$ is not needed and the grid-side current feedback only is adequate to design a stable system with proper selection of the current controller gains, and a critical resonance frequency $\left(f_{\text {res }}=f_{\mathrm{s}} / 6\right)$ where the system will be unstable regardless of the controller that is employed. For the high resonance frequency region, then, a controller gains selection process is presented to provide the effective damping effect and greatest control system bandwidth. However, by connecting an LCL-filter-based inverter system into a weak grid with inductive grid impedance, potential instability may be trigged if the grid impedance variation reduces the resonance frequency to an unstable region $\left(f_{\text {res }} \leq f_{\mathrm{s}} / 6\right)$. Thus, in the general case, to address this challenge, CCF AD scheme due to its effective damping performance and simple implementation, can be useful and effective.

Thus, in this paper, the physical meaning of this damping method and also role that the PWM transport delays play in the effectiveness of that, are well also clarified. It is shown that with regard to the delay effects, the damping performance of proportional CCF is modeled as a frequency dependent virtual impedance which consists of a resistor paralleled with a reactor. If the system actual resonance frequency is higher than $f_{\mathrm{s}} / 6$, where the resistive component of virtual impedance is negative, open-loop unstable poles are introduced to the present current control loop that lead to a non-minimum phase treatment for the system closed-loop system and make easier to be unstable due to the variation of grid impedance. Using different stability analysis, it is shown that to ensure the system stability, the resonance frequency dependent stringent gain margin requirements along with the specific damping term $\left(K_{\mathrm{D}}\right)$ need to be satisfied.

In summary, with the proportional CCF AD scheme, the valid damping region that exhibits high robustness against the variation of grid impedance is limited only to $\left(0, f_{\mathrm{s}} / 6\right)$. To extend the valid damping region and ensure robustness against grid impedance variation, two improved CCF AD methods based on first-order HPF and reduced computation delay mechanism are also introduced in this paper. Theoretical stability analysis and control parameters tuning of the improved CCF AD methods are fully explored.

Acknowledgments: This work has been supported by the Danish Energy Technology Development and Demonstration Program (EUDP) through the Sino-Danish Project "Microgrid Technology Research and Demonstration" (meter.et.aau.dk) and also by the International Science \& Technology Cooperation Program of China, Project Number: 2014DFG62610.

Author Contributions: Iman Lorzadeh and Hossein Askarian Abyaneh are the main researchers who initiated and organized researches reported in the paper and responsible for writing main parts of it, including layout and results. Mehdi Savaghebi, Alireza Bakhshai and Josep M. Guerrero contributed in drafting the paper and analyzed the different presented analytical and simulation results. In addition, their comments on the paper draft have had a big impact on improving its quality. All authors have read and approved the final manuscript.

Conflicts of Interest: The authors declare no conflict of interest.

\section{References}

1. Carrasco, J.M.; Franquelo, L.G.; Bialasiewicz, J.T.; Galvan, E.; Guisado, R.C.P.; Prats, M.A.M.; Leon, J.I.; Moreno-Alfonso, N. Power-electronic systems for the grid integration of renewable energy sources: A survey. IEEE Trans. Ind. Electron. 2006, 53, 1002-1016. [CrossRef]

2. Colak, E.; Kabalci, E.; Fulli, G.; Lazarou, S. A survey on the contributions of power electronics to smart grid systems. Renew. Sustain. Energy Rev. 2015, 47, 562-579. [CrossRef] 
3. Blaabjerg, F.; Teodorescu, R.; Liserre, M.; Timbus, A.V. Overview of control and grid synchronization for distributed power generation systems. IEEE Trans. Ind. Electron. 2006, 53, 1398-1409. [CrossRef]

4. Bouloumpasis, I.; Vovos, P.; Georgakas, K.; Vovos, N.A. Current harmonics compensation in microgrids exploiting the power electronics interfaces of renewable energy sources. Energies 2015, 8, 2295-2311. [CrossRef]

5. Langella, R.; Testa, A.; Et, A. IEEE Recommended Practice and Requirements for Harmonic Control in Electric Power System; IEEE Std. 519-1992/2014; IEEE Standards Association: New York, NY, USA, 2014.

6. IEEE Guide-Adoption of IEC/TR 61000-3-7:2008, Electromagnetic Compatibility (EMC)—Limits—Assessment of Emission Limits for the Connection of Fluctuating Installations to $M V, H V$, and EHV Power Systems; IEEE Standards Association: New York, NY, USA, 2012.

7. Liserre, M.; Blaabjerg, F.; Hansen, S. Design and control of an LCL-filter-based three-phase active rectifier. IEEE Trans. Ind. Appl. 2005, 41, 1281-1291. [CrossRef]

8. Gabe, I.J.; Montagner, V.F.; Pinheiro, H. Design and implementation of a robust current controller for VSI connected to the grid through an LCL-filter. IEEE Trans. Power Electron. 2009, 24, 1444-1452. [CrossRef]

9. Dannehl, J.; Wessels, C.; Fuchs, F.W. Limitations of voltage-oriented PI current control of grid-connected PWM rectifiers with LCL filters. IEEE Trans. Ind. Electron. 2009, 56, 380-388. [CrossRef]

10. Loh, P.C.; Holmes, D.G. Analysis of multiloop control strategies for LC/CL/LCL-filtered voltage-source and current-source inverters. IEEE Trans. Ind. Appl. 2005, 41, 644-654. [CrossRef]

11. Tang, Y.; Loh, P.C.; Wang, P.; Choo, F.H.; Gao, F. Exploring inherent damping characteristic of LCL-Filters for three-phase grid-connected. IEEE Trans. Power Electron. 2012, 27, 1433-1442. [CrossRef]

12. Savaghebi, M.; Jalilian, A.; Vasquez, J.C.; Guerrero, J.M. Secondary control scheme for voltage unbalance compensation in an islanded droop-controlled microgrid. IEEE Trans. Smart Grid 2012, 3, 797-807. [CrossRef]

13. Blasko, V.; Kaura, V. A novel control to actively damp resonance in input LC filter of a three-phase voltage source converter. IEEE Trans. Ind. Appl. 1997, 33, 542-550. [CrossRef]

14. Tang, Y.; Loh, P.C.; Wang, P.; Choo, F.H.; Tan, K.K. Improved one cycle-control scheme for three-phase active rectifiers with input inductor capacitor-inductor filters. IET Power Electron. 2011, 4, 603-614. [CrossRef]

15. Jalili, K.; Bernet, S. Design of LCL-filters of active-front-end two-level voltage-source converters. IEEE Trans. Ind. Electron. 2009, 56, 1674-1689. [CrossRef]

16. Rockhill, A.A.; Liserre, M.; Teodorescu, R.; Rodriguez, P. Grid-filter design for a multi-megawatt medium-voltage voltage-source inverter. IEEE Trans. Ind. Electron. 2011, 58, 1205-1217. [CrossRef]

17. Cao, W.; Liu, K.; Ji, Y.; Wang, Y.; Zhao, J. Design of a four-branch LCL-type grid-connecting interface for a three-phase, four-leg active power filter. Energies 2015, 8, 1606-1627. [CrossRef]

18. Shen, G.; Xu, D.; Cao, L.; Zhu, X. An improved control strategy for grid-connected voltage source inverters with an LCL filter. IEEE Trans. Power Electron. 2008, 23, 1899-1906. [CrossRef]

19. Shen, G.; Zhu, X.; Zhang, J.; Xu, D. A new feedback method for PR current control of LCL-filter-based grid-connected inverter. IEEE Trans. Ind. Electron. 2010, 57, 2033-2041. [CrossRef]

20. He, N.; Xu, D.; Zhu, Y.; Zhang, J.; Shen, G.; Zhang, Y.; Ma, J.; Liu, C. Weighted average current control in a three-phase grid inverter with an LCL filter. IEEE Trans. Power Electron. 2013, 28, 2785-2797. [CrossRef]

21. Twining, E.; Holmes, D.G. Grid current regulation of a three-phase voltage source inverter with an LCL input filter. IEEE Trans. Power Electron. 2003, 18, 888-895. [CrossRef]

22. Dannehl, J.; Fuchs, F.W.; Hansen, S.; Thogersen, P.B. Investigation of active damping approaches for PI-based current control of grid-connected pulse width modulation converters with LCL filters. IEEE Trans. Ind. Appl. 2010, 46, 1509-1517. [CrossRef]

23. Parker, S.G.; McGrath, B.P.; Holmes, D.G. Regions of active damping control for LCL filters. IEEE Trans. Ind. Appl. 2014, 50, 424-432. [CrossRef]

24. Buso, S.; Mattavelli, P. Digital Control in Power Electronics; Morgan and Claypool: San Rafael, CA, USA, 2006.

25. Holmes, D.G.; Lipo, T.A.; McGrath, B.P.; Kong, W.Y. Optimized design of stationary frame three phase AC current regulators. IEEE Trans. Power Electron. 2009, 24, 2417-2426. [CrossRef]

26. Li, X.; Wu, X.; Geng, Y.; Yuan, X.; Xia, C.; Zhang, X. Wide damping region for LCL-type grid-connected inverter with an improved capacitor-current-feedback method. IEEE Trans. Power Electron. 2015, 30, 5247-5259. [CrossRef] 
27. Bao, C.; Ruan, X.; Wang, X.; Li, W.; Pan, D.; Weng, K. Step-by-step controller design for LCL-type grid-connected inverter with capacitor-current-feedback active damping. IEEE Trans. Power Electron. 2014, $29,1239-1253$.

28. Channegowda, P.; John, V. Filter optimization for grid interactive voltage source inverters. IEEE Trans. Ind. Electron. 2010, 57, 4106-4114. [CrossRef]

29. Pena-Alzola, R.; Liserre, M.; Blaabjerg, F.; Sebastian, R.; Dannehl, J.; Fuchs, F.W. Analysis of the passive damping losses in LCL-filter-based grid converters. IEEE Trans. Power Electron. 2013, 28, 2642-2646. [CrossRef]

30. Wu, W.; He, Y.; Blaabjerg, F. An LLCL-power filter for single-phase grid-tied inverter. IEEE Trans. Power Electron. 2012, 27, 782-789. [CrossRef]

31. Wu, W.; He, Y.; Tang, T.; Blaabjerg, F. A new design method for the passive damped LCL and LLCL filter-based single-phase grid-tied inverter. IEEE Trans. Ind. Electron. 2013, 60, 4339-4350. [CrossRef]

32. Wu, W.; Sun, Y.; Huang, M.; Wang, X.; Blaabjerg, F.; Liserre, M.; Chung, H.S. A robust passive damping method for LLCL-filter-based grid-tied inverters to minimize the effect of grid harmonic voltages. IEEE Trans. Power Electron. 2014, 29, 3279-3289. [CrossRef]

33. Beres, R.N.; Wang, X.; Blaabjerg, F.; Bak, C.L.; Liserre, M. A Review of Passive Filters for Grid-Connected Voltage Source Converters. In Proceedings of the IEEE Applied Power Electronics Conference and Exposition, Fort Worth, TX, USA, 16-20 March 2014; pp. 2208-2215.

34. Dannehl, J.; Liserre, M.; Fuchs, F.W. Filter-based active damping of voltage source converters with LCL filter. IEEE Trans. Ind. Electron. 2011, 58, 3623-3633. [CrossRef]

35. Xu, J.; Xie, S.; Tang, T. Active damping-based control for grid-connected LCL-filtered inverter with injected grid current feedback only. IEEE Trans. Ind. Electron. 2014, 61, 4746-4758. [CrossRef]

36. Wang, X.; Blaabjerg, F.; Loh, P.C. Grid-current-feedback active damping for LCL resonance in grid-connected voltage-source converters. IEEE Trans. Power Electron. 2016, 31, 213-223. [CrossRef]

37. He, J.; Li, Y.W. Generalized closed-loop control schemes with embedded virtual impedances for voltage source converters with LC or LCL filters. IEEE Trans. Power Electron. 2012, 27, 1850-1861. [CrossRef]

38. Liu, F.; Duan, S.; Yin, J.; Liu, B.; Liu, F. Parameter design of a two current-loop controller used in a grid-connected inverter system with LCL filter. IEEE Trans. Ind. Electron. 2009, 56, 4483-4491.

39. Li, Y.W. Control and resonance damping of voltage source and current source converters with LC filters. IEEE Trans. Ind. Electron. 2009, 56, 1511-1521.

40. Wessels, C.; Dannehl, J.; Fuchs, F. Active Damping of LCL-Filter Resonance Based on Virtual Resistor for PWM Rectifiers-Stability Analysis with Different Filter Parameters. In Proceedings of the IEEE Power Electronic Specialists Conference, Rhodes, Greece, 15-19 June 2008; pp. 3532-3538.

41. Jia, Y.; Zhao, J.; Fu, X. Direct grid current control of LCL-filtered grid-connected inverter mitigating grid voltage disturbance. IEEE Trans. Power Electron. 2014, 29, 1532-1541.

42. Pan, D.; Ruan, X.; Bao, C.; Li, W.; Wang, X. Capacitor-current-feedback active damping with reduced computation delay for improving robustness of LCL-type grid-connected inverter. IEEE Trans. Power Electron. 2014, 29, 3414-3427. [CrossRef]

43. Zou, Z.; Wang, Z.; Cheng, M. Modeling, analysis, and design of multifunction grid-interfaced inverters with output LCL filter. IEEE Trans. Power Electron. 2014, 29, 3830-3839. [CrossRef]

44. Tang, Y.; Loh, P.C.; Wang, P.; Choo, F.H.; Gao, F.; Blaabjerg, F. Generalized design of high performance shunt active power filter with output LCL filter. IEEE Trans. Ind. Electron. 2012, 59, 1443-1452. [CrossRef]

45. Wang, X.; Blaabjerg, F.; Loh, P.C. Design-Oriented Analysis of Resonance Damping and Harmonic Compensation for LCL-Filtered Voltage Source Converters. In Proceedings of the IEEE International Power Electronics Conference, Hiroshima, Japan, 18-21 May 2014; pp. 216-223.

46. Pan, D.; Ruan, X.; Bao, C.; Li, W.; Wang, X. Optimized controller design for LCL-type grid-connected inverter to achieve high robustness against grid-impedance variation. IEEE Trans. Ind. Electron. 2015, 62, 1537-1547. [CrossRef]

47. Sung-Yeul, P.; Chen, C.; Jih-Sheng, L.; Seung-Ryul, M. Admittance compensation loop control for a grid-tie LCL fuel cell inverter. IEEE Trans. Power Electron. 2008, 23, 1716-1723. [CrossRef]

48. Harnefors, L.; Bongiorno, M.; Lundberg, S. Input-admittance calculation and shaping for controlled voltage-source converters. IEEE Trans. Ind. Electron. 2007, 54, 3323-3334. [CrossRef] 
49. Messo, T.; Jokipii, J.; Makinen, A.; Suntio, T. Modeling the Grid Synchronization Induced Negative-Resistor-Like Behavior in the Output Impedance of A Three-Phase Photovoltaic Inverter. In Proceedings of the 2013 4th IEEE International Symposium on Power Electronics for Distributed Generation Systems (PEDG), Rogers, AR, USA, 8-11 July 2013; pp. 1-7.

50. Goodwin, G.C.; Graebe, S.F.; Salgado, M.E. Control. System Design; Universidad Tecnica Federico Santa Maria: Valparaiso, Chile, 2000.

51. Yepes, A.G.; Freijedo, F.D.; Lopez, O.; Gandoy, J. High-performance digital resonant controllers implemented with two integrators. IEEE Trans. Power Electron. 2011, 26, 563-576. [CrossRef]

52. Pogaku, N.; Green, T.C. Harmonic mitigation throughout a distribution system: A distributed-generator-based solution. IEE Proc. Gener. Transmiss. Distrib. 2006, 153, 350-358. [CrossRef]

53. Wang, X.; Blaabjerg, F.; Loh, P.C. Virtual RC damping of LCL-filtered voltage source converters with extended selective harmonic compensation. IEEE Trans. Power Electron. 2015, 30, 4726-4737. [CrossRef]

54. Liserre, M.; Aquilu, A.D.; Blaabjerg, F. Genetic algorithm-based design of the active damping for an LCL-filter three-phase active rectifier. IEEE Trans. Power Electron. 2004, 19, 76-86. [CrossRef]

55. Liserre, M.; Teodorescu, R.; Blaabjerg, F. Stability of photovoltaic and wind turbine grid-connected inverters for a large set of grid impedance values. IEEE Trans. Power Electron. 2006, 21, 263-272. [CrossRef]

56. Sun, J. Impedance-based stability criterion for grid-connected inverters. IEEE Trans. Power Electron. 2011, 26, 3075-3078. [CrossRef]

57. Yin, J.; Duan, S.; Liu, B. Stability analyses of grid-connected inverter with LCL filter adopting a digital single-loop controller with inherent damping characteristic. IEEE Trans. Ind. Inf. 2013, 9, 1104-1112. [CrossRef]

58. Pena-Alzola, R.; Liserre, M.; Blaabjerg, F.; Sebastian, R.; Dannehl, J.; Fuchs, F.W. Systematic design of the lead-lag network method for active damping in LCL-filter based three-phase converters. IEEE Trans. Ind. Inf. 2014, 10, 43-52. [CrossRef]

59. Malinowski, M.; Bernet, S. A simple voltage sensor-less active damping scheme for three-phase PWM converters with an LCL-filter. IEEE Trans. Ind. Electron. 2008, 55, 1876-1880. [CrossRef]

60. Liu, C.; Zhang, X.; Tan, L.H.; Liu, F. A Novel Control Strategy of LCL-VSC Based on Notch Concept. In Proceedings of the IEEE International Symposium on Power Electronics for Distributed Generation Systems, Hefei, China, 16-18 June 2010; pp. 343-346.

(C) 2016 by the authors; licensee MDPI, Basel, Switzerland. This article is an open access article distributed under the terms and conditions of the Creative Commons Attribution (CC-BY) license (http://creativecommons.org/licenses/by/4.0/). 